\title{
FLORA DE GRÃO-MOGOL, MINAS GERAIS, BRASIL
}

\author{
JOSÉ RUBENS PIRANI, RENATO DE MELLO-SILVA \& ANA MARIA GIULIETTI*
}

\author{
Departamento de Botânica, Instituto de Biociências, Universidade de São Paulo, \\ Caixa Postal 11461, 05422-970 - São Paulo, SP, Brasil \\ * Endereço atual: Departamento de Ciências Biológicas, Universidade Estadual de Feira de Santana, \\ BR 116, km 3, 44031-460 - Feira de Santana, BA, Brasil
}

\begin{abstract}
Flora of Grão-Mogol, Minas Gerais, Brasil). The general data on the project of survey of the vascular flora of the Serra de Grão-Mogol, a part of the Espinhaço Range of mountains, are presented. They are based upon collections obtained during 21 expeditions to that area in northeast of the State of Minas Gerais. More than 100 researchers worked in the identification and compilation of the taxonomic treatments for the families, each one including identification keys, descriptions and illustrations of genera and species, as well as data on their geographic distribution and habitats. In this introduction to the Flora, basic data on the geomorphology, climate and vegetation of the Serra de Grão-Mogol are presented, followed by description of the methods employed, general fur mat of the taxonomic treatments, and a brief discussion of the main results obtained. In the region occur 15 families of ferns, with 22 genera and 40 species, one species of gymnosperms, and 113 families of angiosperms, with 444 genera and 1032 species. At least 59 species of flowering plants are endemic to the region of Grão-Mogol. The five richest families are Leguminosae (104 spp.), Compositae (76 spp.), Melastomataceae (43 spp.), Rubiaceae (42 spp.), and Gramineae (41 spp.). Following to this introductory article, the taxonomic treatments will be presented in alphabetical order.
\end{abstract}

Resumo - (Flora de Grāo-Mogol, Minas Gerais, Brasil). Os dados gerais sobre o projeto de levantamento da flora vascular da Serra de Grão-Mogol são apresentados, com base em coleçōes realizadas durante 21 expedições a essa área situada no nordeste de Minas Gerais, na Cadeia do Espinhaço. Foram envolvidos mais de 100 pesquisadores na identificação e preparo dos trabalhos sobre cada família, contendo chaves de identificação, descrições e ilustrações dos gêneros e espécies, além de dados sobre sua distribuição geográfica e hábitats. Nesse artigo introdutório à Flora, são apresentados dados geomorfológicos, climáticos e vegetacionais sobre a Serra de Grão-Mogol, e descritos os métodos utilizados, o formato dos tratamentos taxonômicos e discutidos os principais resultados obtidos. Foram encontradas na regiāo 15 famílias de pteridófitas, com 22 gêneros e 40 espécies, uma espécie de gimnosperma, e 113 famílias de angiospermas, com 444 gêneros e 1032 espécies. Pelo menos 59 espécies de angiospermas são endêmicas da regiāo de Grão-Mogol. As cinco famílias mais ricas em espécies são Leguminosae (104 spp.), Compositae (76 spp.), Melastomataceae (43 spp.), Rubiaceae (42 spp.) e Gramineae (41 spp.). Os trabalhos sobre cada família sāo apresentados a seguir a esse artigo, em ordem alfabética, devendo ser publicados em volumes subseqüentes os demais trabalhos.

Key words: florística, Cadeia do Espinhaço, campo rupestre.

\section{Introdução}

Aspectos gerais sobre a Cadeia do Espinhaço e seus campos rupestres

Desde meados do século XIX a vegetação das serras da Cadeia do Espinhaço, no centro de Minas Gerais e Bahia, tem atraído a atenção de naturalistas, principalmente pela riqueza de sua flora e peculiaridade da paisagem. Também conhecida como Serra Geral (King 1956), a Cadeia do Espinhaço constitui um conjunto orográfico que se estende por cerca de $1100 \mathrm{~km}$ entre os limites $20^{\circ} 35^{\prime}$ e $11^{\circ} 11^{\prime} \mathrm{S}$, com altitudes médias entre 800 e 1800 m (Magalhães 1954). Limitada ao sul pela Serra de Ouro Branco, em Minas Gerais, e ao norte por serras na região de Senhor do Bonfim, esse setor do Escudo Cristalino Brasileiro constitui o divisor de águas entre os rios tributários do São Francisco e os que se dirigem para o Atlântico (Derby 1906, Moreira 1977, Renger 1979, Abreu 1984) (Fig. 1).

Distinguem-se na cadeia um setor mineiro, cujo limite norte fica nas elevações isoladas na área de Monte Verde e Montezuma, separado do setor baiano, normalmente denominado Chapada Diamantina, por um considerável hiato de terrenos baixos onde as elevações acima de $1000 \mathrm{~m}$ ficam reduzidas e bem afastadas entre si (Fig. 1).

Os imensos afloramentos rochosos do Espinhaço são muito antigos (os blocos estruturais datam do Précambriano, segundo Abreu 1984), resistentes aos processos de erosão diferencial, pois foram modelados 
geralmente em rochas silicosas, notadamente os quartzitos e arenitos (Moreira 1977). Predominam na região solos arenosos e rasos (Joly 1970).

Entre as diversas formações vegetais ali encontradas, destacam-se os campos rupestres (Magalhães 1966), que aparecem geralmente em altitudes superiores a 900 $m$, adjacentes ou entremeando os grandes afloramentos rochosos dessas serras. A importância especial dos campos rupestres e da vegetação rupícola nas serras da Cadeia do Espinhaço é devida não só à sua predominância em extensão, mas às interessantes adaptações especiais de muitas de suas espécies, e à elevada diversidade genética ali concentrada, com alto grau de endemismo (Joly 1970, Giulietti et al. 1987, 1997). Embora nos tradicionais sistemas de classificação da vegetação brasileira ou sulamericana (e.g. Cabrera \& Willink 1973) os campos rupestres sejam geralmente incluídos como fácies do cerrado, alguns autores distinguiram os campos rupestres como formação bem individualizada. Eiten (1983) reconheceu 24 tipos vegetacionais na sua classificação, dentre eles o campo rupestre, mas posteriormente apresentou esse campo como um dos tipos de vegetação ocorrentes "na província do cerrado" (Eiten 1990). Usando enfoque diferente dos anteriores, baseado estritamente em aspectos florísticos, Prance (1994) propôs nova classificação de províncias fitogeográficas (fitocórias) para a vegetação neotropical, onde distinguiu a fitocória dos campos rupestres. Segundo o autor, esse centro de endemismo teria distribuição descontínua, em forma de "arquipélago", devido à sua restrição a topos de montanhas isoladas (v. Prance 1994). No sistema de classificação do IBGE (Veloso et al. 1991) os campos rupestres constam como "refúgios vegetacionais (relíquias)".

Estudos botânicos na Cadeia do Espinhaço - bases e estratégia de ação dos projetos floristicos, com ênfase em Minas Gerais

A vegetação das serras da Cadeia do Espinhaço vem sendo estudada por mais de duas décadas por botânicos do Departamento de Botânica do IB-USP, com colaboração de taxonomistas da Universidade Estadual de Campinas, Instituto de Botânica de São Paulo e de outras instituições nacionais e estrangeiras, destacando-se dentre as últimas o Royal Botanic Gardens de Kew, Inglaterra. Mais recentemente, também botânicos da Universidade Estadual de Feira de Santana, Bahia, e da Universidade Federal da Bahia, engajaram-se nos projetos de pesquisa no Espinhaço, notadamente na Chapada Diamantina. Os estudos desenvolvidos por esses biólogos envolvem análise florística, taxonomia de famílias específicas, morfologia e anatomia, fitoquímica, biologia floral, ecologia - especialmente fitofisionomia e estrutura das comunidades. Alguns zoólogos e gene- ticistas daquelas instituições têm também desenvolvido trabalhos na região.

Os aspectos fundamentais que têm motivado os estudos botânicos e biogeográficos nesse conjunto orográfico foram assim sintetizados por Lohmann \& Pirani (1996):

1. o fato do Espinhaço constituir o centro de diversidade de numerosos gêneros de muitas famílias, como Compositae, Melastomataceae, Ericaceae, Leguminosae, e mesmo de famílias inteiras como Velloziaceae, Eriocaulaceae e Xyridaceae, sendo essas últimas incomuns ou mesmo ausentes em outras formações brasileiras;

2. sua flora muito rica, especialmente a campestre, que contém elevado grau de endemismos;

3. a diversidade da paisagem, basicamente condicionada à topografia acidentada dos terrenos;

4. os interessantes padrões de distribuição geográfica das espécies, com vários tipos de disjunções, decorrentes do caráter "insular" das serras que compõem a cadeia, ilhadas parcialmente dentro do domínio morfoclimático dos cerrados (o que se verifica na maior parte do setor mineiro do Espinhaço) e parcialmente dentro do domínio das caatingas (no setor baiano e na porção setentrional do setor mineiro da cadeia), conforme já ressaltaram Giulietti \& Pirani (1988) e Giulietti et al. (1997).

A linha básica de estudo da flora da Cadeia do Espinhaço tem seguido um programa de expedições exploratórias a várias serras, acompanhadas de amostragem mais intensiva em alguns setores principais, localizados de sul ao norte, que são estudados com maior profundidade. Assim, na Bahia foram escolhidas as regiōes de Mucujê (Serra do Sincorá, Harley \& Simmons 1986), do Pico das Almas (Stannard 1995), do Morro do Pai Inácio e Serra da Chapadinha (Guedes \& Orge 1998) e da Serra de Catolés, esta última presentemente em fase de compilação de listagem florística por pesquisadores do Royal Botanic Gardens, Kew, da Universidade Estadual de Feira de Santana e do IB-USP. Em Minas Gerais, foram selecionados a Serra do Cipó, o Planalto de Diamantina, a Serra do Cabral e a Serra de GrãoMogol. Na Serra do Cipó, Giulietti et al. (1987) encontraram, numa área de ca. $200 \mathrm{~km}^{2}, 1590$ espécies de plantas vasculares, comprovando a alta diversidade florística desse setor do Espinhaço. De 1987 a 2002, os tratamentos taxonômicos detalhados de 50 famílias e seis táxons infra-familiares da Flora da Serra do Cipó foram publicados no Boletim de Botânica da USP. Trabalhos com ênfase nas formações florestais dessa serra e do Planalto de Diamantina foram realizados por Meguro et al. (1996a, b). Para a Serra do Ambrósio (Município de Rio Vermelho), foram apresentadas a caracterização fitofisionômica e estrutural (Meguro et al. 


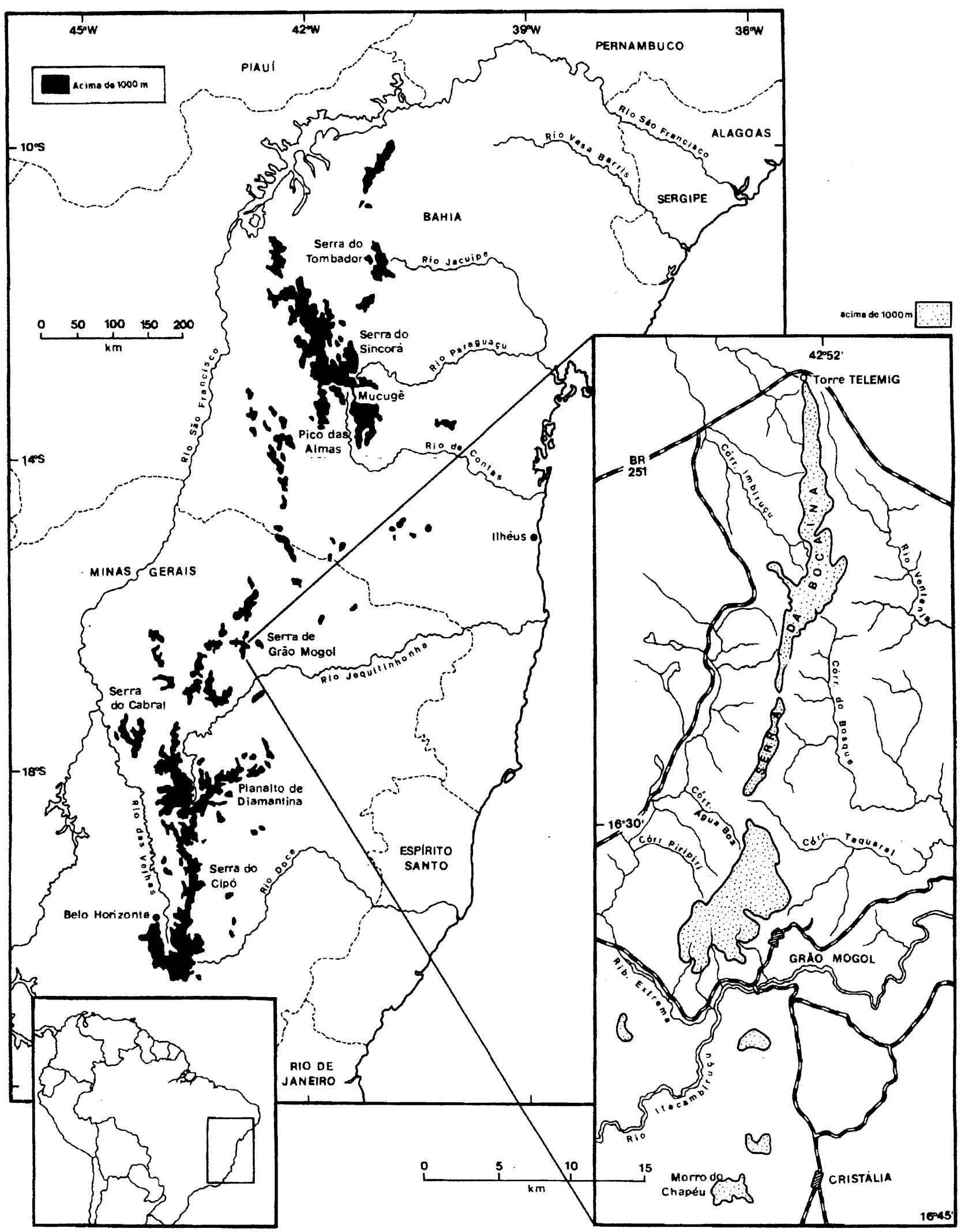

Fig. 1. Cadeia do Espinhaço, Minas Gerais e Bahia, Brasil, da qual estão destacados os terrenos acima de 1000 m de altitude, e mostrando em detalhe, à direita, a região onde está situada a Serra de Grão-Mogol. Mapa à esquerda modificado de Giulietti $\ell l$ al. (1997); mapa da direita modificado da Folha SE-23-X-B, 1:250.000 (IBGE 1982). 
1994) e a lista da flora com dados biogeográficos (Pirani et al. 1994). Investigações florísticas na Serra do Cabral e nas várias sub-regiões do Planalto de Diamantina têm tido prosseguimento.

Pesquisadores de outras instituições, que não as citadas anteriormente, têm também apresentado contribuições para o conhecimento da flora de áreas serranas do Espinhaço, destacando-se para Minas Gerais as listas florísticas das Serras de Grão-Mogol e da Ibitipoca (Ferreira \& Magalhães 1977), da Serra do Caraça (Ferreira et al. 1978), do Parque Estadual do Itacolomi, Ouro Preto/Mariana (Peron 1989), da Serra da Piedade (Brandão \& Gavilanes 1990), da Serra do Itabirito (Brandão et al. 1991), de Barão de Cocais (Brandão \& Silva-Filho 1993) e do município de Diamantina (Brandão et al. 1995).

No presente trabalho, são apresentados dados detalhados sobre a flora vascular da Serra de Grão-Mogol. O estudo da vegetação dessa serra, situada no nordeste de Minas Gerais, deveu-se, além dos aspectos anteriormente citados, à sua localização ímpar, em posição intermediária e disjunta entre as serras da Cadeia do Espinhaço em Minas Gerais e Bahia (Fig. 1), já próxima da porção meridional do Domínio das Caatingas. Apesar da semelhança fisionômica geral existente entre a vegetação dessa área e de outras do Espinhaço, devido à abundância de praticamente as mesmas famílias e gêneros, a região possui uma vegetação característica e composição florística peculiar em nível específico, com grande número de endemismos, representados muitas vezes por populações bem restritas.

\section{Histórico dos estudos botânicos na Serra de Grão-Mogol}

Antes do início do presente projeto, a região de GrãoMogol havia sido pouco pesquisada do ponto de vista botânico. Em julho de 1818, Carl P. F. von Martius e Johann Baptist von Spix aproximaram-se da região, visitando a Serra da Canastra ou de Botumirim, que fica ao sul de Grão-Mogol. Mais de um século depois, em 1926, a região foi visitada pelo geólogo e botânico Álvaro da Silveira, cujas coletas renderam algumas novas espécies de Eriocaulaceae como Paepalanthus graomogolensis Silveira, P. extremensis Silveira e Syngonanthus grao-mogolensis Silveira.

Em 1938, por lá passou a expedição de Friedrich Markgraf, Antonio C. Brade e Henrique de MelloBarreto e novamente algumas novas espécies foram descritas a partir das coletas então efetuadas, e.g. Blechnum bradei Markgraf, Pitcairnia bradei Markgraf, Vellozia bradei Schulze-Menz, V. markgrafii SchulzeMenz, Barbacenia markgrafii Schulze-Menz (v. Markgraf 1940). Lychnophora markgravii G.M. Barroso, uma no- tável Compositae arborescente endêmica da região, foi também descrita com base em material dessa expedição (v. Barroso 1956).

Em 1960, Bassett Maguire e Celia K. Maguire, do New York Botanical Garden, organizaram juntamente com Geraldo Mendes Magalhães uma expedição a GrãoMogol que resultou na descrição de muitas outras espécies novas. Tal fato se repetiu com a expedição de 1969 organizada pelo New York Botanical Garden, Instituto de Pesquisas e Experimentação do Norte e Universidade de Brasília, liderada por Howard S. Irwin.

A partir de então, no final dos anos 70 e início dos 80 , tiveram início algumas viagens esporádicas levadas a cabo por pesquisadores do Jardim Botânico do Rio de Janeiro, Museu Botânico Municipal de Curitiba e Universidade de São Paulo. Dentro do presente projeto, após uma primeira visita exploratória à área em 1981, iniciaram-se em 1986 uma série de coletas sistemáticas na região, envolvendo pesquisadores da Universidade de São Paulo e Royal Botanic Gardens, Kew, visando a elaboração da Flora de Grão-Mogol (v. Apêndice 1).

Até o momento, o único trabalho de listagem da flora da região é o apresentado por Ferreira \& Magalhães (1977) que relacionaram 104 espécies distribuídas em 28 famílias. Mais recentemente, foi concluída uma dissertação de mestrado sobre as Velloziaceae de Grão-Mogol, com parte dos dados publicados por Mello-Silva (1995). Outras contribuições recentes ao conhecimento da flora de Grão-Mogol envolvem, fundamentalmente, descrições de novos táxons, podendo-se citar as elaboradas por Lourteig (1987), Mello-Silva \& Menezes (1988), Cordeiro (1989), Cavalcanti (1989, 1998), Wasshausen (1990), Mello-Silva (1991), Sobral (1993), Hind (1994), A.B. Martins (1995), E. Martins (1995), Yamamoto (1995), Bittrich (1996), Kameyama (1996), Kirkbride (1997), Borba et al. (1998), Pruski \& Hind (1998) e Wallnöfer (1999).

\section{Situação geográfica, relevo e clima da região de Grão-Mogol}

A região de Grão-Mogol está compreendida entre os limites de $16^{\circ} 20^{\prime}$ e $16^{\circ} 38^{\prime}$ de latitude $S$ e $43^{\circ}$ e $42^{\circ} 49^{\prime}$ de longitude Oeste (Fig. 1). Recentemente (22/09/1998) foi decretado o Parque Estadual da Serra da Bocaina nessa região, compreendendo uma área aproximada de 33.324,72 ha, pertencente ao município de GrãoMogol. O parque inicia-se ao norte junto à Torre da Telemig, situada às margens da rodovia BR 251 , descendo para o sul abrangendo fundamentalmente terrenos de cotas altimétricas acima de $700 \mathrm{~m}$, até próximo ao rio Itacambiruçu, o maior da região (Fig. 2). Na porção centro-setentrional do parque, localmente designada 
Serra da Bocaina ou Serra do Barão, as áreas serranas estendem-se por faixa estreita no sentido N-S, tendo a leste as cabeceiras do rio Ventania e vários de seus afluentes, como o Córrego do Bosque, e a oeste as cabeceiras dos córregos Imbiruçu, Capim Doce e Água Boa. Mais para o sul, perto da cidade de Grão-Mogol (Fig. 2, 3C), as áreas serranas são um pouco mais extensas em largura, constituindo a Serra de Grão-Mogol propriamente dita, e vários dos riachos que ali nascem (Escurinha, Jambeiro, Córrego da Bonita, Ribeirão da Morte) percorrem curto caminho até desembocarem no rio Itacambiruçu (Fig. 1, 2). Todos esses cursos d'água fazem parte da bacia do Jequitinhonha.
A altitude varia de cerca de $650 \mathrm{~m}$, nas baixadas próximas ao rio Itacambiruçu, até as serranias entre 900 e $1100 \mathrm{~m}$ s.m., com poucos pontos culminantes atingindo entre 1215-1299 m. s.m.

Segundo Moreira \& Camelier (1977), a Serra de Grão-Mogol domina as amplas áreas aplainadas circundantes (Fig. 3A), pois os relevos estruturais postos em saliência pela erosão diferencial apresentam escarpas íngremes, que sugerem falhas. A serra é constituída por rochas representadas pelos quartzitos e arenitos da Série Itacolomi, muito resistentes à erosão, com estratificação entrecruzada. Pelas encostas distribuem-se numerosos blocos de conglomerados, contendo seixos

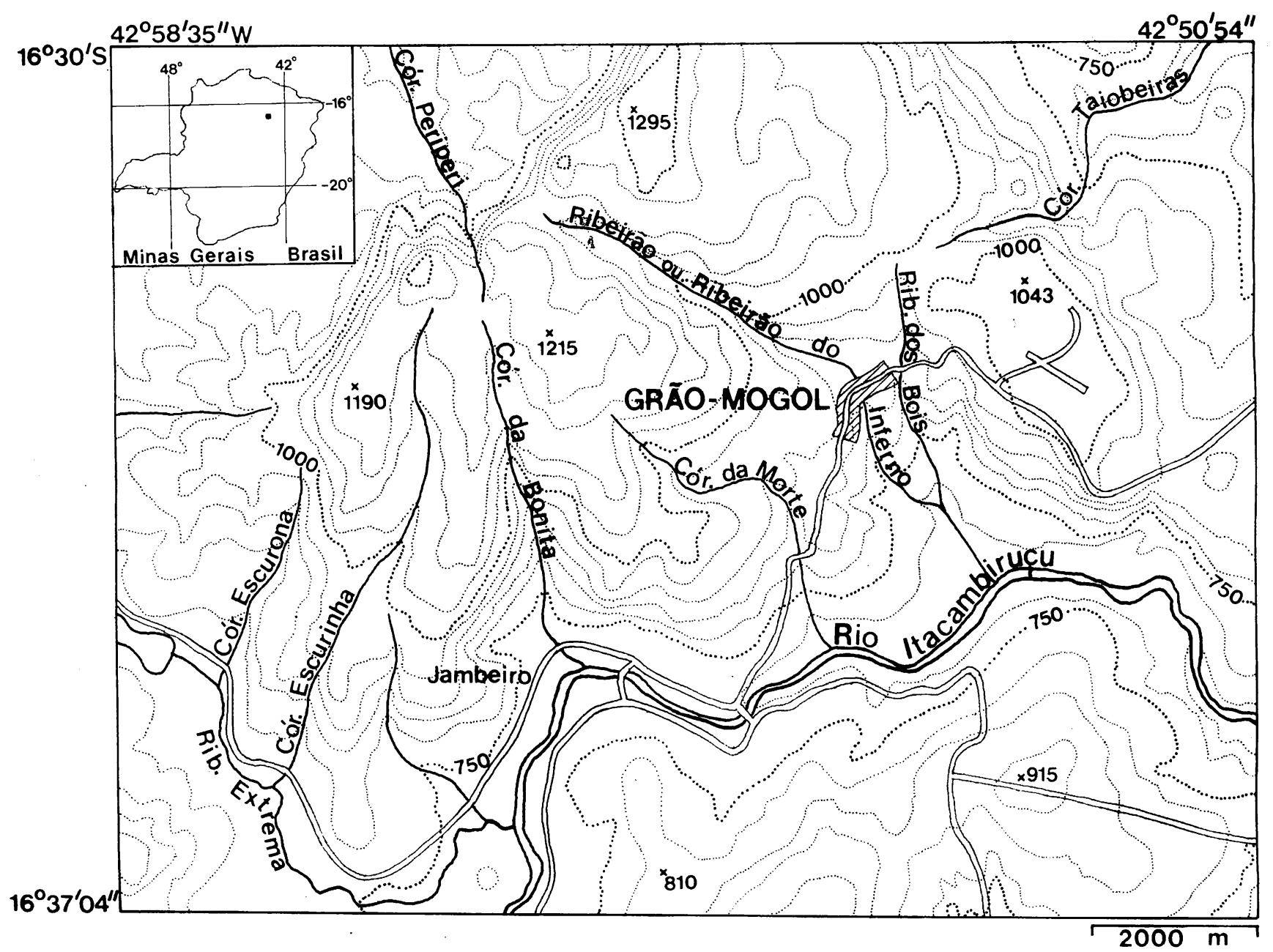

Fig. 2. Região de Grão-Mogol abrangida pelo maior esforço de coletas para a compilação da Flora. Modificado da Folha SE-23-X-B-V, 1:100.000 (IBGE 1980). 
de quartzo e itacolomitos. Assim, a serra é formada por cristas remanescentes de antigas superfícies cristalinas (proterozóicas) que sofreram dobramentos, falhas, intrusões e erosão diferencial.

O clima na região de Grão-Mogol é tropical, variando de quente (nas altitudes inferiores a $900 \mathrm{~m}$ ) a subquente (nas altitudes acima daquela cota), sempre com inverno ameno e verão muito longo, de setembro a março. A pluviosidade tem distribuição anual marcadamente sazonal, com estação chuvosa coincidente com o verão, e estação seca de 5 meses, de maio a setembro, caracterizando-se assim o subtipo climático "clima semiúmido" (Nimer 1977).

Como a região Norte de Minas Gerais faz parte do conhecido Polígono das Secas Nordestino, durante a estação chuvosa podem ocorrer períodos de "veranico" (falta de chuva) de uma semana até trinta dias. Contudo, em Grão-Mogol, a presença das elevações serranas ocasiona nebulosidade e temperaturas mais amenas localmente, atenuando um pouco dos rigores climáticos reinantes no Vale do Jequitinhonha.

Os solos das áreas campestres da região, como de resto na Cadeia do Espinhaço, são predominantemente rasos, ácidos e pobres em nutrientes e matéria orgânica. Exceção notável são as baixadas úmidas, onde grande acúmulo de material orgânico pode ser encontrado. As áreas cobertas por matas ou cerrados apresentam solos mais profundos.

\section{Caracterização da vegetação de Grão-Mogol}

As condições fisiográficas e situação da Serra de Grão-Mogol no Vale do Jequitinhonha, já próxima aos limites meridionais do domínio das caatingas, em posição intermediária e disjunta entre as serras da Cadeia do Espinhaço em Minas Gerais e Bahia (Fig. 1), propiciam o desenvolvimento de formações vegetais em mosaico, com áreas de cerrado, floresta semi-caducifólia e carrascos, mantendo-se, contudo, como no resto do Espinhaço, o predomínio da formações campestres de altitude, notadamente campos rupestres.

De modo geral, poder-se-ia descrever a paisagem predominante na região como aquela formada por vegetação arbustiva entre grandes blocos rochosos em desagregação, entremeados com areia grossa depositada por água pluvial e agrupamentos de arbustos e espécies subarbustivo-herbáceas rupícolas formando pequenas manchas de campo rupestre (Fig. 3D, E). É aí que ocorrem a maioria das Velloziaceae da regiāo (Mello-Silva 1995), podendo ser destacada Vellozia spiralis L.B. Sm., freqüente nas encostas rochosas acima de 900 $\mathrm{m}$ s.m. e com hábito dracenóide alcançando até $3,5 \mathrm{~m}$ de altura (Fig. 4D). Nesses mesmos ambientes aparecem arvoretas esguias como Lychnophora markgravii
G.M. Barroso, L. granmogolense (Duarte) D.J.N. Hind e Vernonia hatschbachii (H.Rob.) D.J.N. Hind, e arvoretas robustas como Aspidosperma dispermum Müll.Arg. (Apocynaceae), Clusia obdeltifolia Bittrich (Guttiferae, Fig. 4E), Eremanthus polycephalus (DC.) MacLeish e Wunderlichia mirabilis Riedel ex Baker (Compositae, Fig. 6C ), espécie caducifólia, com grandes capítulos densamente lanuginosos. Arbustos de Acosmium brachystachium (Benth.) Yakovl. (Leguminosae) e Casearia eichleriana Sleum. (Flacourtiaceae) são muito comuns, assim como Norantea adamantium Cambess. (Marcgraviaceae), com seus longos ramos decumbentes sobre os grandes rochedos. Destacam-se ainda a grande cactácea Pilosocereus fulvilanatus Buin \& Brederoo, com robustos cladódios glaucos (Fig. 3E); grandes agrupamentos de Euphorbia attastoma Rizzini, uma Euphorbiaceae cactiforme densa e profusamente ramosa (Fig. 4H); arbustos como Esenbeckia irwiniana Kaastra (Rutaceae) e o pequeno imbiruçu, Pseudobombax campestre (Mart.) A. Robyns (Bombacaceae, Fig. 4F), duas espécies notáveis e comumente associadas; arvoretas de folhagem dourada de Persea aurata Miq. (Lauraceae), arbustos de folhagem escura de Matayba marginata Radlk. (Sapindaceae); arbustos de folhagem imbricada e esbranquiçada de Hyptis passerina Mart. e H. piranii Harley (Labiatae), arbustos de Harpalyce parvifolia Irwin \& Arroyo (Leguminosae, Fig. 5G) com folhas cinéreas e flores alaranjadas; pequenos arbustos de Disynaphia praeficta (B.L. Rob.) R.M. King \& H. Rob. (Compositae, Fig. 6F); diversas espécies de Chamaecrista (Leguminosae), sendo as mais comuns C. cytisoides (Collad.) Irwin \& Barneby, com folhas de tons vináceo e violáceo, C. desvauxii (Collad.) Killip, C. celiae (Irwin $\&$ Barneby) Irwin \& Barneby, grande arbusto de folhas orbiculares, C. stillifera (Irwin \& Barneby) Irwin \& Barneby, C. tephrosiifolia (Benth.) Irwin \& Barneby com folíolos de ápice pungente. São comuns ainda Senna corifolia (Benth.) Irwin \& Barneby, conhecida na região como "pau-de-vidro" e usada como lenha, S. rugosa (G. Don) Irwin \& Barneby (Leguminosae), Baccharis platypoda DC. (Compositae) e Kielmeyera regalis Saddi (Guttiferae) de grandes flores rosas. Das ervas e subarbustos, podem ser citadas Begonia grisea A.DC. (Begoniaceae, Fig. 6B), erva robusta coberta de indumento pruinoso alvo e com caule vermelho, Cuphea ericoides Cham. \& Schltdl. (Lythraceae), Calea semirii Pruski \& D.J.N. Hind (Compositae), diversas Declieuxia (Rubiaceae), Eriocaulaceae como Paepalanthus grao-mogolensis A. Silv. (Fig. 4G) e Syngonanthus elegans (Bong.) Ruhl., Cactaceae como Micranthocereus auriazureus Buin. \& Brederoo (Fig. 5A), com botões florais cor-de-rosa, conhecido como "rabode-raposa" e muito procurado para exportação, e ainda densos e abundantes subarbustos da Sebastiania nummularifolia Cordeiro (Euphorbiaceae). Deve-se ressaltar ainda nesse ambiente a presença comum de 


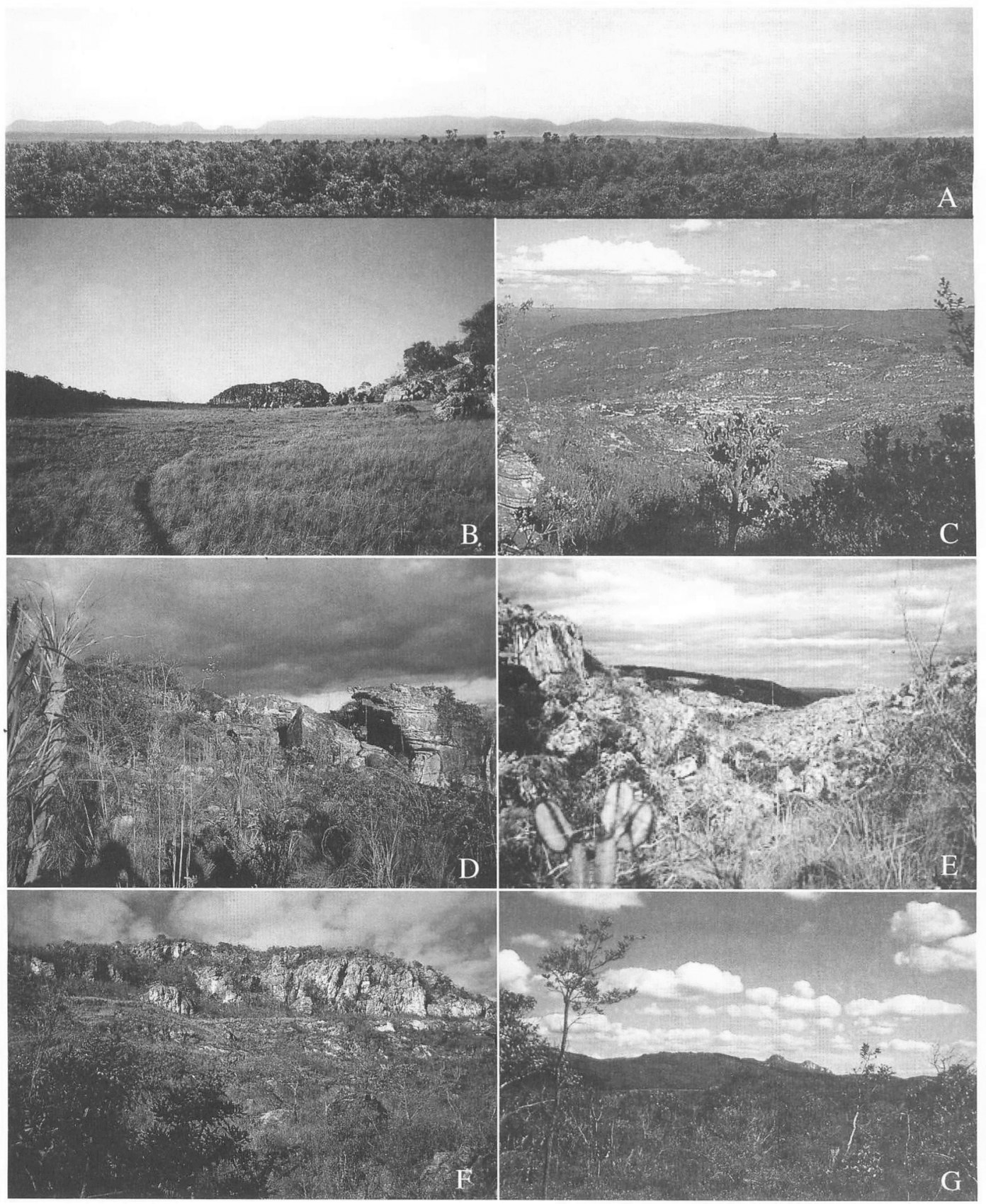

Fig. 3. Aspectós gerais da região de Grão-Mogol, Minas Gerais, Brasil: A. perfil topográfico mostrando a sudeste o vale do rio Itacambiruçu (1), a Serra de Grão-Mogol (2), duas áreas onde foi concentrado o trabalho de campo, e mais ao norte a Serra da Bocaina (3). B. campo limpo de cimeira, no topo da serra, ca. $1100 \mathrm{~m}$ s.m.; C. vista geral da cidade de Grão-Mogol em meio à paisagem dominada pelos campos rupestres e afloramentos; D. vegetação arbóreo-arbustiva entre os afloramentos, com exemplar de Vellozia glauca Pohl (Velloziaceae) à frente, à esquerda; E. encostas rochosas com a cactácea Pilosocereus fulvilanalus (Buining \& Brederoo) Ritter em primeiro plano à esquerda; F. paredões rochosos do Morro do Jambeiro, com vegetação rupícola e patamares cobertos por brejos estacionais; G. carrasco sobre terrenos adjacentes ao vale do Rio Itacambiruçu, observando-se ao fundo o Morro do Chapéu. (A-F. fotos de R. Mello-Silva; G. foto de J.R. Pirani). 


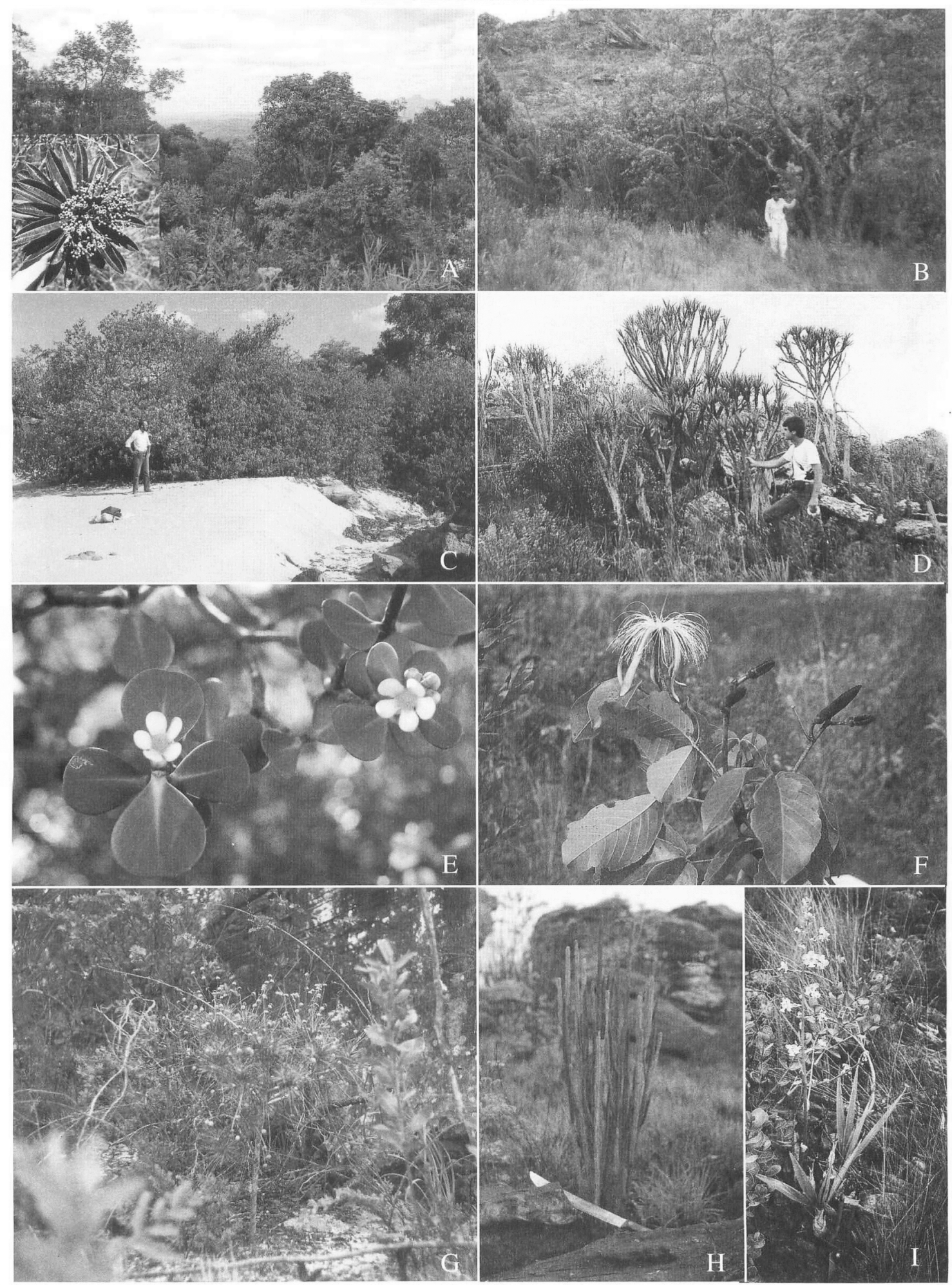

Fig. 4. Algumas espécies e aspectos gerais da vegetação de Grão-Mogol, Minas Gerais, Brasil: A. capão no alto da serra, observando-se à direita um exemplar de Hortia arlorea Engl. (Rutaceae), com suas inflorescências corimbosas vistas no detalhe à direita; B. campos do alto da serra, com faixa de vegetação lenhosa ripária com os característicos colmos virgados da bambusóide Chusquea nutans L.G. Clark (Gramineae); C. dunas de areia quartzosa nas margens do rio Itacambiruçu, com densa moita de Hirtella martiana Hook. f. (Chrysobalanaceae); D. vegetação rupícola destacando-se população de Vellozia spiralis L.B. Sm. (Velloziaceae); E. ramo florido de Clusia obdellifolia Bittrich (Guttiferae); F. ramo florido de Pseudobombax campestre (Mart. \& Zucc.) A. Robyns (Bombacaceae); G. exemplar florido de Paepalanthus graomogolensis Silveira (Eriocaulaceae); H. Euphorbia altastoma Rizzini (Euphorbiaceae); I. planta florida de Cyrlopodium edmundoi Pabst (Orchidaceae). (A, B, D, E, G, H - fotos de J.R. Pirani; C, F, I - fotos de R. Mello-Silva). 
Serjania suborbicularis Radlk. (Sapindaceae), liana delgada que se alastra sobre as rochas. Embora a maioria das espécies rupícolas explore as fendas das rochas, muitas delas crescem diretamente sobre a superfície rochosa, como a orquídea Cyrtopodium edmundoi Pabst (Fig. 4I) e Barbacenia reflexa L.B. Sm. \& Ayensu (Velloziaceae, Fig. 6D).

No topo aplanado das serras, encontram-se os característicos campos de cimeira (Fig. 3B). Localmente denominados "vargens", esses campos estendem-se por terrenos de areia branca com poucas ondulacões, onde gramíneas e ciperáceas formam um estrato mais ou menos contínuo, com touceiras de Vellozia spp. (Velloziaceae), pequenos arbustos e subarbustos de Croton spp. (Euphorbiaceae), Cuphea spp. (Lythraceae), e diversas outras espécies, como Pseudobrickellia brasiliensis (Spreng.) R.M. King \& H. Rob. (Compositae), Cambessedesia hilariana (Kunth) DC. (Melastomataceae), Chamaecrista aurivilla (Benth.) Irwin \& Barneby e $C$. cytisoides (Collad.) Irwin \& Barneby (Leguminosae). Aí merecem especial referência a Sauvagesia elegantissima A. St.-Hil. (Ochnaceae), arbusto esquálido, pauci-ramoso, com diminutas rosetas de folhas distribuídas ao longo do caule muito alongado, e Paepalanthus regalis Mart. ex Koern. (Fig. 5C, Eriocaulaceae) com rosetas robustas e capítulos característicos. Pequenos af loramentos rochosos despontam em meio aos campos de cimeira, e aí é comum a presença de Emmotum nitens Miers (Icacinaceae), Vellozia spp. e Aechmea bromelifolia (Rudge) Baber e Tillandsia spp. (Bromeliaceae). Ao contrário de outras áreas da Cadeia do Espinhaço, como o Planalto de Diamantina, onde os campos de cimeira ocupam grandes extensões, em Grão-Mogol esses campos são estreitos e descontínuos, conseqüência da grande desagregação sofrida por esta parte da Cadcia do Espinhaço, como afirma Abreu (1984) sobre outras áreas do Espinhaço quando comparadas a Diamantina.

Em áreas mais planas das vertentes, margeando riachos e onde ocorre maior acúmulo de água e matéria orgânica, desenvolvem-se brejos, geralmente estacionais (Fig. 3F), caracterizados por grande diversidade de espécies herbáceas como Cephalostemon riedelianus Koern. (Rapateaceae), Xyrisspp. (Xyridaceae), Lagenocarpus rigidus (Kunth) Nees, Rhynchospora speciosa (Kunth) Boeck. e várias outras espécies de Cyperaceae; Philodendron uliginosum Mayo (Araceae), Siphanthera arenaria (DC.) Cogn. (Melastomataceae), Utricularia spp. (Lentibulariaceae), Burmannia bicolor Mart. e outras Burmanniaceae, diversas espécies de Eriocaulaceae e de Orchidaceae, principalmente Habenaria, além da robusta Drosera graomogolensis T. Silva (Droseraceae, Fig. 5D) e almofadas de Sphagnum spp. (Sphagnaceae). Nas margens pedregosas de riachos que percorrem os campos da serra, é comum a presença de arbustos de Callianidra fasciculata Benth. (Leguminosae), Hirtella gracilipes (Hook. f.) Prance (Chrysobalanaceae), Macairea radula (Bonpl.) DC. e Trembleya hatschbachii Wurdack \& E. Martins (Melastomataceae, Fig. 5E), esta com folhagem brilhante e vistosas flores amarelas.

As áreas mais baixas que circundam as regiōes serranas, onde o solo o permite, seja sobre latossolos ou areias quartzosas, são dominadàs por cerrado arbóreo aberto com estrato herbáceo-subarbustivo ralo a denso. São aí encontradas entre outras espécies típicas deste tipo de vegetação: Annona coriacea Mart. e A. crassiflora Mart: (Annonaceae), Tabebuic aurea (Silva Manso) Benth. \& Hook. e T. ochracea (Cham.) Sandw. (Bignoniaceae), Caryocar brasiliense Cambess. (Caryocaraceae), Miconia albicans (Sw.) Triana (Melastomataceae), Hymenaea stigonocarpa Mart. ex Hayne, Andira laurifolia Benth., Bauhinia pulchella Benth., Bowdichia virgilioides Kunth, Tachigali aurea Tul. e Stryphnodendron adstringens (Mart.) Coville (Leguminosae), Byrsonima sericea DC. (Malpighiaceae), Campomanesia adamantium (Cambess.) O. Berg, Eugenia punicifolia (Kunth) DC. e Psidium guineense Sw. (Myrtaceae), Matayba marginata Radlk. (Sapindaceae), Qualea grandiflora Mart. e Vochysia rufa Mart. (Vochysiaceae) e numerosos exemplares da palmeira acaulescente Attalea geraensis Barb. Rodr. Aqui ocorre também a cactácea Arrojadoa dinae Buining \& Brederoo (Fig. 5B).

As linhas de drenagem são acompanhadas por matas ciliares cuja composição inclui árvores de grande e médio porte como Ormosia arborea (Vell.) Harms (Leguminosae), Protium spruceanum March. (Burseraceae), Alchornea triplinervia (Spreng.) Müll. Arg. e Richeria grandis Vahl (Euphorbiaceae), Tapirira guianensis Aubl. (Anacardiaceae), Calophyllum brasiliense Cambess. (Guttiferae), Hedyosmum brasiliense Mart. ex Miq. (Chloranthaceae), Inga vera Willd. (Leguminosae), Molopanthera panniculata Turcz. (Rubiaceae) e Vochysia acuminata Bong. (Vochysiaceae). Na orla das matas ciliares encontram-se comumente numerosas arvoretas de Trembleya parviflora (D.Don) Cogn. (Melastomataceae), e naquelas de altitude mais elevada aparecem os esguios colmos de Chusquea nutans L.G. Clark (Gramineae) (Fig. $4 \mathrm{~B})$. Essas matas podem apresentar-se às vezes bem abertas como as do vale do riacho Ribeirão, onde são encontrados, subespontâneos, muitos indivíduos de jambo (Syzygium jambos (L.) Alston, Myrtaceae). Como parte dos estratos inferiores podem ser encontrados grande quantidade de arbustos e subarbustos como Calliandra fasciculata Benth. (Leguminosae), Miconia elegans Cogn. (Melastomataceae), Diplusodon smithii Lourt. e Cuphea teleandra Lourt. (Lythraceae), delgadas palmeiras (Geonoma brevispatha Barb. Rodr., Palmae) e samambaias como Cyathea delgadii Sternb. (Cyatheaceae), Polypodium. spp. (Polypodiaceae) e Blechnum spp. (Blechnaceae). 

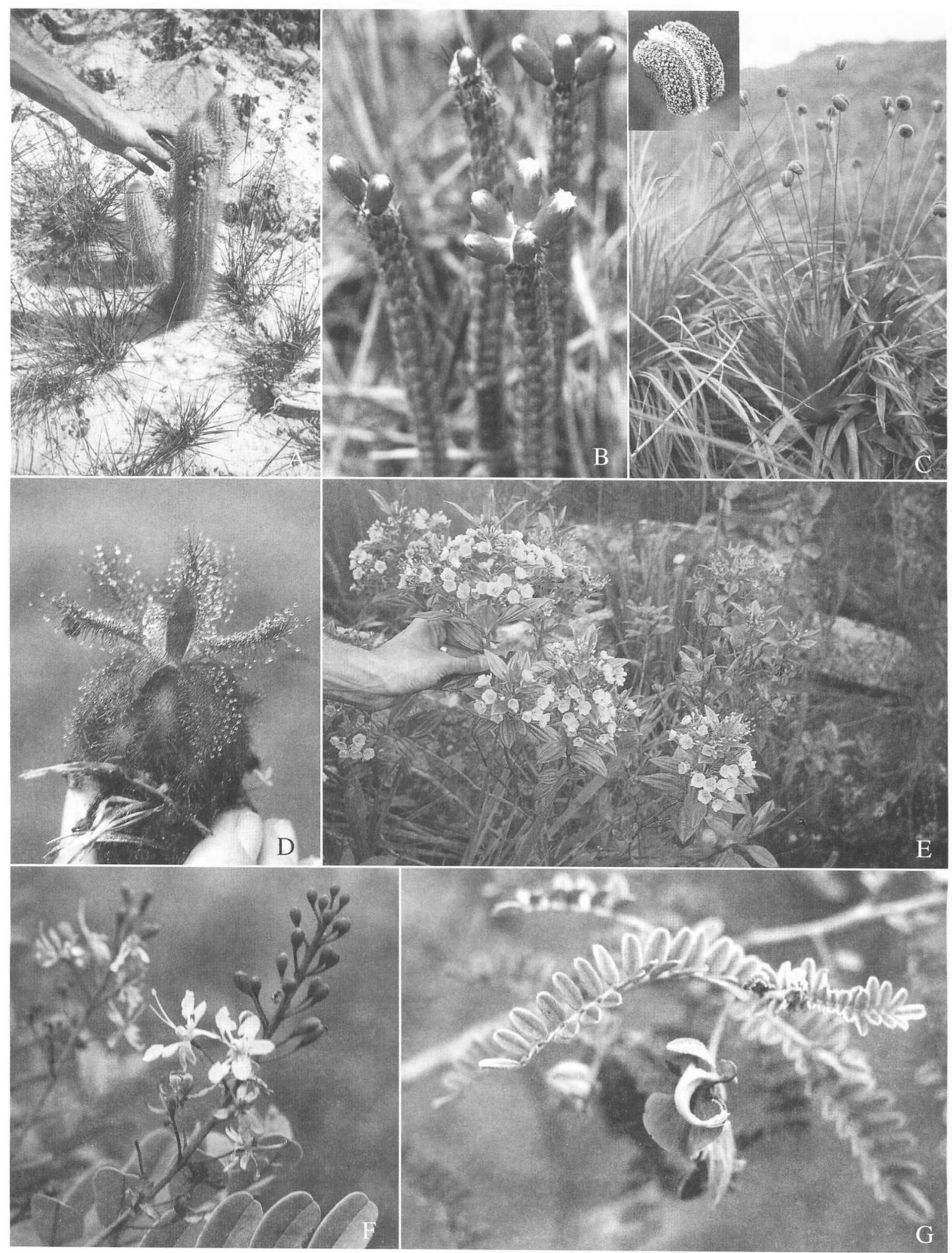

Fig. 5. Espécies características da flora de Grão-Mogol, Minas Gerais, Brasil: A. Micranthocereus auriazureus Buining \& Brederoo (Cactaceae) em solo francamente arenoso; B. cladódios floridos de Arrojadoa dinute Buining \& Brederoo (Cactaceae); C. Paupalanthus regalis Mart. ex Koern. (Eriocaulaceae), hábito com detalhe de capítulo; D. roseta da espécie carnívora Drosera graomogolensis T. Silva (Droseraceae); E. arbusto florido de Trembleya halschbachii E. Martins (Melastomataceae); F. ramo florido de Moldenhawera emarginala (Spreng.) L.P.Queiroz \& R.Allkin (Leguminosae); G. ramo florido de Harpalyce parvifolia Irwin \& Arroyo (Leguminosae). (A. foto de R. Mello-Silva; B-G. fotos de J.R. Pirani). 
Tapetes de musgos revestem cascas de árvores, rochas e solo no interior da mata, sobretudo nas partes mais úmidas, podendo ser citados os gêneros Octoblepharum, Campylopus, Frullania e Sphagnum. É freqüente também a ocorrência de espécies de hemiparasitas variadas (Psittacanthus robustus Mart., Loranthaceae; Phoradendron spp., Viscaceae) na copa das árvores. Nas baixadas úmidas da chamada Serra do Barão e próximo ao Córrego do Bosque, existe denso e extenso buritizal (Mauritia flexuosa L.f., Palmae), associado a matas cilares ou não (Fig. 6A).

Em alguns lugares, as matas ciliares vão unir-se, encosta acima, a capões de mata (Fig. 4A). Estes estão localizados nos topos dos morros ou encostas pouco inclinadas, sem blocos rochosos, e são aparentemente remanescentes de matas originais mais extensas, em grande parte transformadas, por ação antrópica, em capoeiras e capoeirões. Nessas matas destaca-se a presença abundante e conspícua - pelo tronco espesso com casca ocre-rosada - dos monjoleiros (Pterodon emarginatus Vog., Leguminosae). Aí também são encontradas grandes árvores de Diplotropis ferruginea Benth., Copaifera langsdorffii Desf. (Leguminosae), Aspidosperma discolor A.DC. e A. dispermum Müll.-Arg. (Apocynaceae), e espécies de menor porte como Guatteria notabilis MelloSilva \& Pirani (Annonaceae), Schefflera macrocarpa (Cham. \& Schltdl.) Frodin (Araliaceae), Hortia arborea Engl. (Rutaceae), conhecida localmente como "limad'anta", notável pelas inflorescências corimbosas rosadas características (Fig. 4A), Persea rufotomentosa Nees \& Mart. (Lauraceae), Senna silvestris (Vell.) Irwin \& Barneby e S. splendida (Vog.) Irwin \& Barneby (Leguminosae), a última, escandente com grandes flores amarelas, e várias espécies de Malpighiaceae, Myrtaceae, Rubiaceae e Erythroxylaceae. Em vários desses capões, cuja orla foi perturbada por atividade humana, estabelece-se densa e extensa população de Moldenhazuera emarginata (Spreng.) L.P. Queiroz \& R. Allkin (Leguminosae, Fig. 5F), arbusto avantajado, com folhas e inflorescências com indumento ferrugíneo.

Em áreas extensas das encostas, sobretudo nas bases voltadas para o vale do rio Itacambiruçu, a mata ou cerrado dão lugar a uma vegetação arbóreo-arbustiva localmente denominada "carrasco" (Fig. 3G), com plantas densamente ramificadas de porte médio, situadas sobre substrato arenoso a arenoso-pedregoso, entremeado por grandes blocos rochosos que aumentam em quantidade com a altitude. Aí se encontram especialmente Exellodendron gardneri (Hook.f.) Prance (Chrysobalanaceae), Andira vermifuga Mart. ex Benth., Anadenanthera colubrina (Vell.) Brenan, Bauhinia pulchella Benth., $B$. aff. nitida Benth., Mimosa gemmulata Barneby e Moldenhazvera emarginata (Spreng.) L.P. Queiroz \& R. Allkin (Leguminosae, Fig. 5F), Ocolea glaucina
(Meisn.) Mez (Lauraceae), Diplusodon rosmarinifolius A. St.-Hil. (Lythraceae), Guatteria rupestris Mello-Silva \& Pirani (Fig. 6G), Duguetia furfuracea (A. St.-Hil.) Benth. \& Hook f., Annona coriacea Mart. e A. crassiflora Mart. (Annonaceae), Vantanea obovata (Nees \& Mart.) Benth. (Humiriaceae), Mouriri cf. glazioviana Cogn. (Melastomataceae) com frutos comestíveis conhecidos como "mandapuçá", Cybianthus detergens Mart. (Myrsinaceae), Myrciaria glanduliflora (Kiaersk.) Mattos \& Legrand (Myrtaceae), Ouratea hatschbachii K. Yamamoto (Ochnaceae), Heisteria citrifolia Engl. e Ximenia coriacea Engl. (Olacaceae), e as lianas Bredemeyera martiana A.W. Benn. (Polygalaceae), Serjania paradoxa Radlk. (Sapindaceae) e Trigonia nivea Cambess. (Trigoniaceae). Muito comuns nesses carrascos são árvores tortuosas de Terminalia fagifolia Mart. (Combretaceae). Nos esparsos afloramentos rochosos que ocorrem em meio aos carrascos próximos ao Ribeirão das Mortes podem ser encontradas touceiras da Vellozia ciliata. L.B. Sm. (Velloziaceae), com suas folhas pungentes. Esses intrincados carrascos de Minas Gerais e outras partes do Brasil Central são pouco estudados, embora já fossem mencionados por naturalistas como Saint-Hilaire (1837, p. 5) e Glaziou (1905, p. 5). Mais recentemente, Meguro et al. (1994) caracterizaram a fisionomia, composição florística e estrutura de carracos da Serra do Ambrósio, no Planalto de Diamantina, Minas Gerais, e Harley (1995) tratou os carrascos da região do Pico das Almas, na Chapada Diamantina, Bahia, como formaçòes de transição cerrado-caatinga.

Enquanto a margem direita do rio Itacambiruçu pode ser acompanhada por larga faixa florestal ripária, onde as maiores árvores são monjoleiros (Pterodon emarginatus Vog., Leguminosae), na sua margem esquerda, assim como nas margens dos córregos afluentes (área mais intensivamente coberta pelo presente levantamento) quase não existe cobertura florestal, ou esta é muito descontínua. Porém, as espécies ali existentes, que ocorrem entre rochas ou nas amplas dunas das margens do rio (Fig. 4C), diferenciam-se da vegetação circundante. Nesse tipo de vegetação podem ser encontradas, por exemplo, árvores e arvoretas de Ceiba jasminodora (A. St.-Hil.) K. Schum. (Bombacaceae), Helietta glazioviii (Engl.) Pirani (Rutaceae), Aspidosperma macrocarpum Mart. (Apocynaceae), Jacaranda brasiliana (Lam.) Pers., Tabebuia ochracea (Cham.) Standl. e T. aurea (Silva Manso) S. Moore (Bignoniaceae); duas arvoretas de folhas fortemente conchadas: Kielmeyera appariciana Saddi (Guttiferae) e Merianthera sipolisii (Glaz. \& Cogn.) Wurdack (Melastomataceae); arbustos viscosos de Pavonia grazielae Krapov. (Malvaceae, Fig. 6E); moitas densas de Hirtella martiana Hook. f. (Fig. 4C) e H. glandulosa Spreng. (Chrysobalanaceae); Cuphea brachiatta Koehne (Lythraceae) com flores amarelas e Barbacenia riparia 


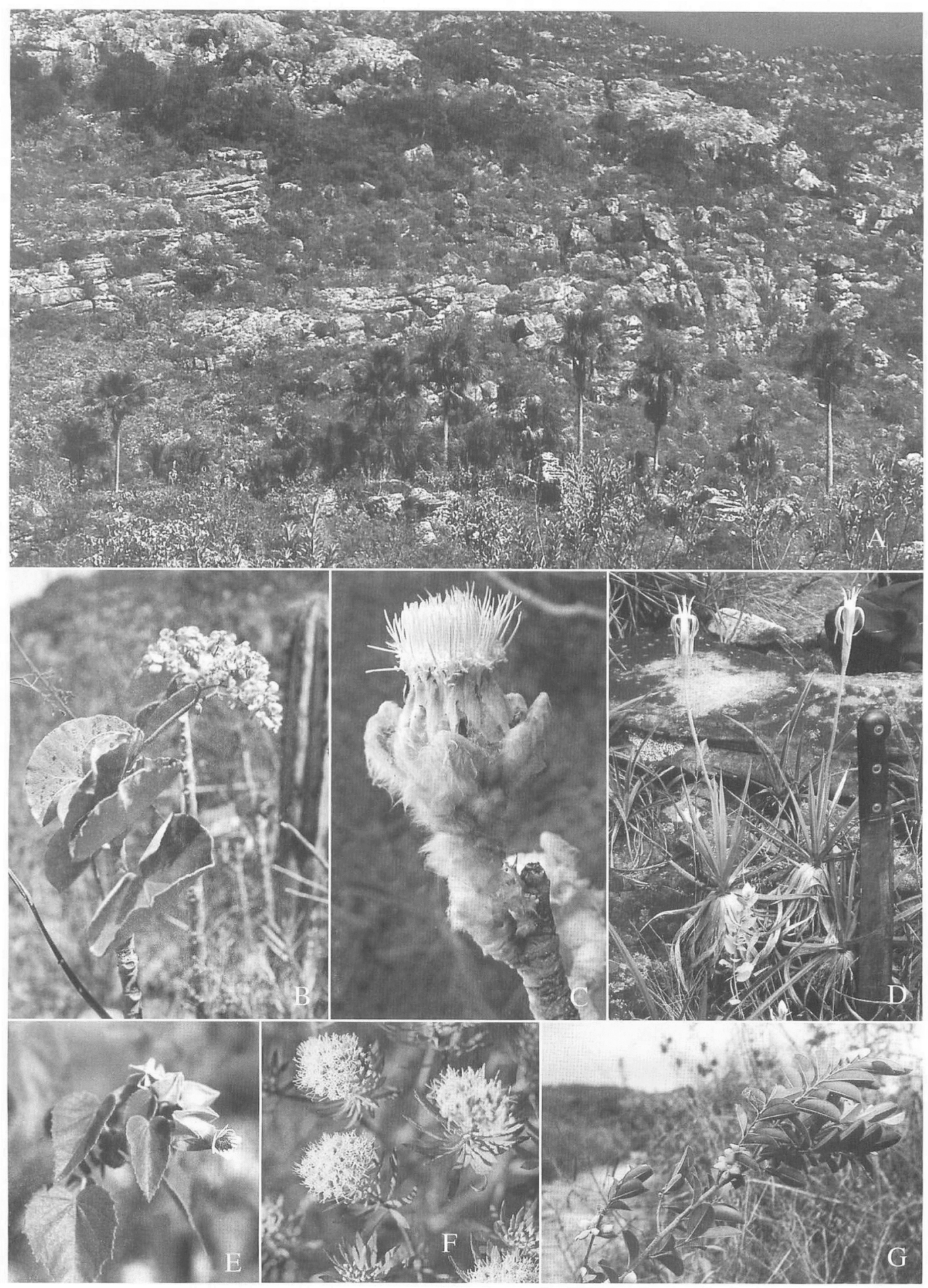

Fig. 6. Algumas espécies e aspectos gerais da vegetação de Grão-Mogol, Minas Gerais, Brasil: A. encostas rochosas da Chapada do Bosque, com buritis (Mauritia flexuosa L.f., Palmae) ao longo de curso d'água; B. ramo florido de Begonia grisea A.DC. (Begoniaceae); C. capítulo de Wunderlichia mirabilis Riedel ex Baker (Compositae); D. rosetas floridas de Barbacenia reflexa L.B. Sm. \& Ayensu (Velloziaceae); E. ramo florido de Pavonia grazielae Krapov. (Malvaceae); F. ramo florido de Disynaphia praeficla (B.L. Rob.) R.M. King \& H. Rob. (Compositae); G. ramo florido de Gualeria rupestris Mello-Silva \& Pirani (Annonaceae). (A. foto de A.C. Marcato; B, C, E, F. fotos de J.R. Pirani; D, G. foto de R. Mello-Silva). 
(Menezes \& Mello-Silva) Mello-Silva, pequena Velloziaceae que forma touceiras pulviniformes sobre os ban$\cos$ de areia da beira-rio.

Em suma, a vegetação da região em torno de GrãoMogol é fisionômica e estruturalmente muito diversificada e as freqüentes e extensas áreas transicionais entre as formações mais típicas supra-descritas dificultam uma classificação satisfatória, com limites precisos entre elas.

\section{Plano geral e métodos da Flora}

\section{Coleçôes}

O material básico utilizado na preparação da Flora foi obtido durante expediçóes coordenadas pela equipe da USP à região, iniciadas em dezembro de 1981. Um total de 21 expediçōes foram realizadas, resultando num vulto superior a 3700 espécimes coletados (ver Apêndice 1). A coleção principal está depositada no Herbário do Departamento de Botânica do IB-USP (SPF), com duplicatas distribuídas para os especialistas envolvidos e para as instituições colaboradoras, notadamente HUEFS, K, SP e UEG (siglas segundo Holmgren et al. 1990). Coleções relevantes feitas na região encontram-se ainda nos herbários MBM e RB, e de modo geral também foram examinadas pelos colaboradores.

\section{Delimitação da área de coletas}

Os sítios visitados para amostragem estão inseridos numa área total de cerca de $400 \mathrm{~km}^{2}$, nas proximidades da cidade de Grão-Mogol. Coletas em todas as estações do ano foram realizadas principalmente no trecho delimitado pelas coordenadas $16^{\circ} 30^{\prime} 00^{\prime}-16^{\circ} 37^{\prime} 04^{\prime \prime} \mathrm{S}$ e $42^{\circ} 50^{\prime} 54^{\prime \prime}-42^{\circ} 58^{\prime} 35^{\prime \prime} \mathrm{W}$ (área central da Fig. 2, ca. 100 $\mathrm{km}^{2}$ ), entre 1981 e 1998, abrangendo principalmente a região plana e montanhosa ao longo do rio Itacambiruçu, margem esquerda, no trecho que vai da desembocadura do córrego Escurona à desembocadura do Córrego da Morte, compreendendo terrenos com altitudes na cota de 700 a $1000 \mathrm{~m}$ s.m.; a bacia do Córrego da Morte, de 650 a $1150 \mathrm{~m}$; a bacia do Ribeirão dos Bois, de 850 a $1000 \mathrm{~m}$ até a nascente do córrego Taiobeiras; a área próxima à torre de TV, ca. 1000-1050m; o vale, as escarpas e montanhas próximas ao riacho Ribeirão, de 850 a $1050 \mathrm{~m}$ e o topo da serra, de 1100 a $1250 \mathrm{~m}$.

Foram também realizadas diversas visitas menos regulares a localidades mais ao norte (até a Serra do Barão), a noroeste (rio Ventania e Chapada do Bosque) e ao sul (elevaçōes da margem direita do rio Itacambiruçu, até Cristália e Morro do Chapéu).

\section{Compilação dos trabalhos taxonômicos}

A identificação do material e a preparação dos trabalhos florísticos envolveu a participação de mais de
100 pesquisadores, listados na Tabela 1 (exceto em 3 famílias em que só aparece na tabela o nome dos coordenadores). Foi dada prioridade à consulta a especialistas, mas muitos grupos foram estudados por alunos de pós-graduação, aperfeiçoamento e mesmo iniciação científica, especialmente em famílias com carência de especialista disponível, ou em grupos representados na área por poucas espécies. Algumas famílias vultosas, como Euphorbiaceae e Leguminosae, tiveram a participação de vários pós-graduandos sob a coordenação de um especialista. Muitos desses pós-graduandos, hoje já titulados e provavelmente estabelecidos como profissionais em outra instituição, aparecem citados na Tabela 1 como ligados ao Herbário SPF devido ao fato de terem executado esses trabalhos ainda ali.

O estudo das famílias de plantas vasculares estão sendo apresentados em ordem alfabética (exceto grupos ainda em estudo), em volumes do Boletim de Botânica da USP, seguindo um padrão geral de formato. Adotaram-se as famílias segundo Cronquist (1981), exceto Leguminosae (Fabaceae s.l.), Alstromeriaceae, Amaryllidaceae e Herreriaceae (ao invés de Liliaceae s.l.), e ainda exceto pela adoção dos nomes tradicionais Compositae, Gramineae, Guttiferae, Palmae e Labiatae (alternativos a Asteraceae, Poaceae, Clusiaceae, Arecaceae e Lamiaceae, respectivamente). Em cada família, uma bibliografia fundamental para a realização de cada trabalho é apresentada no início, exceto no tratamento mais extenso (Leguminosae), onde existe literatura citada também sob táxons infra-familiares. Chaves conduzem à identificação de gêneros e simultaneamente às espécies do mesmo presentes na área, exceto nas duas maiores famílias, Compositae e Leguminosae, onde existem chaves para subfamílias ou tribos, e os táxons estão apresentados nessa seqüência. Descrições sucintas de gêneros e espécies visam facilitar sua identificação, além de expressar a circunscrição aceita pelo taxonomista.

As descrições são seguidas pela citação dos materiais examinados, sendo referidos apenas coletor e número - geralmente um número dentro da Coleção Flora de Campos Rupestres - CFCR - e herbários depositários. As informações detalhadas sobre localidade $\mathrm{e}$ hábitat das séries de espécimes coletados sob $C F C R$, em 15 expedições, constam do Apêndice 1, assim corno sobre os espécimes coletados sob números de coletores em outras 6 expedições do grupo do presente projeto.

Para cada espécie, apresentam-se breves comentários sobre a distribuição geográfica e hábitats de ocorrência e floração/frutificação em Grão-Mogol.

Com raras exceções, são apresentadas ilustrações de partes vegetativas e/ou reprodutivas de todas as espécies tratadas na flora. 
Tabela 1. Relação de famílias de plantas vasculares presentes em Grão-Mogol, Minas Gerais (com número de gêneros e espécies) e taxonomistas com instituição ou herbário de origem (siglas segundo Holmgren et al. 1990).

* indica estimativa preliminar, pois o tratamento taxonômico ainda não está concluído.

\begin{tabular}{|c|c|c|c|}
\hline Tíxon & AUTORES - HERIBÁRIO OU INSTITUICLĨO & GÊNEROS & EsPÉCIES \\
\hline Pteridófitas (15 famílias) & J. Prado \& P.H. Labiak - SP & 22 & 40 \\
\hline \multicolumn{4}{|l|}{ Gimnospermas } \\
\hline Podocarpaceae & J.R. Pirani - SPF & 1 & 1 \\
\hline \multicolumn{4}{|l|}{ Angiospermas } \\
\hline Acanthaceae & C. Kameyama - SPF & 2 & 3 \\
\hline Alismataceae & E.S. Gimarães \& R. Mello-Silva - SPF & 1 & 1 \\
\hline Alstroemeriaceae & M.R.M. Mimura \& A.M. Giulietti - SPF & 1 & 1 \\
\hline Amaranthaceae & A. Furlan - HRCB & $3 *$ & $9 *$ \\
\hline Amaryllidaceae & M.R.M. Mimura \& A.M. Giulietti - SPF & 1 & 1 \\
\hline Anacardiaceae & J.R. Pirani - SPF & 5 & 6 \\
\hline Annonaceae & R.Mello-Silva \& I.R. Pirani - SPF & 4 & 8 \\
\hline Apocynaceae (exceto Asclepiadoideae) & A.A. Oliveira \& J.R. Pirani - SPF & 10 & 17 \\
\hline Apocynaceae-Asclepiadoideae & A. Rapini, R. Mello-Silva - SPF \& M.L. Kawasaki - SP & 8 & 22 \\
\hline Aquifoliaceae & M. Groppo Jr. \& J.R. Pirani - SPF & 1 & 3 \\
\hline Araceae & C.M. Sakuragui - SPF & 2 & 3 \\
\hline Araliaceae & P. Fiaschi \& J.R. Pirani - SPF & 1 & 1 \\
\hline Aristolochiaceae & M. Batalha \& M.C. Jorge - SPF & 1 & 1 \\
\hline Begoniaceae & E.L. Jacques - UFMS & 1 & 1 \\
\hline Bignoniaceae & L.G. Lohmann \& J.R.Pirani - SPF & 9 & 19 \\
\hline Bombacaceae & G.L. Esteves - SP & 3 & 4 \\
\hline Boraginaceae & E. Melo \& F. França - HUEFS & 2 & 4 \\
\hline Bromeliaceae & M.G.L. Wanderley \& R.C. Forzza - SP & 9 & 18 \\
\hline Burmanniaceae & T.R.S. Silva \& R. Mello-Silva - SPF & 1 & 4 \\
\hline Burseraceae & J.R. Pirani - SPF & 1 & 2 \\
\hline Cactaceae & D.C. Zappi \& N.P. Taylor - K & 9 & 10 \\
\hline Campanulaceae & S.A.P. Godoy - SPFR & 1 & 1 \\
\hline Capparaceae & G. Stan \& A.M. Giulietti - SPF & 1 & 2 \\
\hline Caryocaraceae & F.A. Vitta - SPF & 1 & 1 \\
\hline Cecropiaceae & J.P. Caranta - GUA & 1 & 1 \\
\hline Celastraceae & M. Groppo Jr. \& J.R. Pirani - SPF & 2 & 2 \\
\hline Chloranthaceae & J.R. Pirani - SPF & 1 & 1 \\
\hline Chrysobalanaceae & M.C. Assis - SPF & 3 & 6 \\
\hline Combretaceae & M.L. Kawasaki - SP & 1 & 1 \\
\hline Commelinaceae & M.T.V. Campos \& T.R. Silva - SPF & 3 & 5 \\
\hline Compositae & D.J.N. Hind - K & 38 & 82 \\
\hline Convolvulaceae & $\mathrm{R}$ Simão-Bianchini - SP & $5 *$ & $15 *$ \\
\hline Connaraceae & E. Forero - COL & 1 & 2 \\
\hline Cunnoniaceae & H.N.Mesquita, J.R.L. Godoy \& J.R. Pirani - SPF & 1 & $\overline{2}$ \\
\hline Cyperaceae & F. Vitta (coord.) - UEC & $10^{*}$ & $34 *$ \\
\hline Dilleniaceae & F.B. Mendonça \& P.T. Sano - SPF & 3 & 5 \\
\hline Dioscoreaceae & G. Pedralli - CETEC & 1 & 7 \\
\hline Droseraceae & T.R.S. Silva - SPF & 1 & 4 \\
\hline Ebenaceae & P.T. Sano - SPF & 1 & 2 \\
\hline Ericaceae & L.S. Kinoshita - UEC & $2 *$ & $6 *$ \\
\hline Eriocaulaceae & A.M. Giulietti, P.T. Sano \& L.R. Parra - SPF & $4 *$ & $26 *$ \\
\hline Erythroxylaceae & M.I. Loyola - PEUFR & 1 & $6^{*}$ \\
\hline Euphorbiaceae & I. Cordeiro (coord.) - SP & 15 & 38 \\
\hline Flacourtiaceae & M.C. Assis - SPF & 1 & 5 \\
\hline Gentianaceae & I. Cordeiro - SP & 3 & 6 \\
\hline Gesneriaceae & A. Chautems - G & 1 & 1 \\
\hline Gramineae & H.Longhi-Wagner \& B.H. Todeschini - ICN & 19 & 41 \\
\hline Guttiferae & J.P. Cometti \& J.R. Pirani - SPF & 3 & 6 \\
\hline Herreriaceae & M.R.M. Mimura \& A.M. Giulietti - SPF & 1 & 1 \\
\hline Hippocrateaceae & A.Furlan - HRCB & 3 & 3 \\
\hline Humiriaceae & L. Rossi - SP & $3 *$ & $3 *$ \\
\hline Icacinaceae & M.A. Farinaccio, D.C. Silva \& R. Camacho - SPF & 1 & 1 \\
\hline Iridaceae & N.S. Chukr - SPF & 4 & 8 \\
\hline Juncaceae & M. Groppo Jr. \& J.R. Pirani - SPF & 1 & 1 \\
\hline Krameriaceae & M.C. Assis - SPF & 1 & 1 \\
\hline Labiatae & G. Dominguez - SPF \& R.M. Harley - K & 6 & 15 \\
\hline
\end{tabular}


Tabela 1. Continuação

\begin{tabular}{|c|c|c|c|}
\hline TÁXON & AUTORES - HERBÁRIO OU INSTITUIÇĀO & GÊNEROS & ESPÉCIES \\
\hline Lauraceae & A.C. Marcato - SPF \& H. van der Werff - MO & $4 *$ & $10^{*}$ \\
\hline Leg. Caesalpinioideae & L.P. Queiroz (coord.) - HUEFS & 8 & 35 \\
\hline Leg. Mimosoideae & L.P. Queiroz (coord.) - HUEFS & 9 & 25 \\
\hline Leg. Papilionoideae & L.P. Queiroz (coord.) - HUEFS & 23 & 44 \\
\hline Lentibulariaceae & E. Fromm-Trinta $-\mathrm{R}$ & 2 & 10 \\
\hline Loganiaceae & D.C. Zappi - K & 3 & 6 \\
\hline Loranthaceae & B.L. Stannard - K \& C.T. Rizzini - RB & 3 & 10 \\
\hline Lythraceae & T.B. Cavalcanti - CEN & 3 & 12 \\
\hline Malpighiaceae & M.C.H. Mamede - SP & 6 & 26 \\
\hline Malvaceae & G.L. Esteves - SP & $5^{*}$ & $14 *$ \\
\hline Marcgraviaceae & P.T. Sano - SPF & 1 & 1 \\
\hline Melastomataceae & A.B. Martins (coord.) - UEC & $17 *$ & $43^{*}$ \\
\hline Meliaceae & E.L. Jacques - UFMS \& H.L. Ozório $\mathrm{F}^{\circ}-\mathrm{SPF}$ & 2 & 2 \\
\hline Molluginaceae & A. Furlan - HRCB & 1 & 1 \\
\hline Monimiaceae & M.V.L. Pereira-Moura \& A.L. Peixoto - RBE & 2 & 2 \\
\hline Moraceae & F. França \& E. Melo - HUEFS & 2 & 3 \\
\hline Myrsinaceae & P. Fiaschi, A.Q. Lobão \& J.S. Christiano - SPF & 2 & 6 \\
\hline Myrtaceae & M.L. Kawasaki - SP & 9 & 34 \\
\hline Nyctaginaceae & A. Furlan - HRCB & $1^{*}$ & $2 *$ \\
\hline Ochnaceae & K. Yamamoto - UEC \& C. Sastre - P & 3 & 8 \\
\hline Olacaceae & M.C. Assis - SPF & 2 & 3 \\
\hline Oleaceae & F.P. Gomes \& J.R. Pirani - SPF & 1 & 1 \\
\hline Onagraceae & A. Grillo \& A.M. Giulietti - SPF & 1 & 4 \\
\hline Opiliaceae & M. Groppo Jr. \& J.R. Pirani - SPF & 1 & 1 \\
\hline Orchidaceae & F. Barros \& F. Pinheiro - SP & 17 & 30 \\
\hline Oxalidaceae & A. Conceição \& A.M. Giulietti - SPF & 1 & 4 \\
\hline Palmae & A.C. Marcato \& J.R. Pirani - SPF & 4 & 5 \\
\hline Passif loraceae & F. Vitta - UEC & 1 & 5 \\
\hline Phytolaccaceae & A. Furlan - HRCB & 1 & 1 \\
\hline Piperaceae & E.C. Gonçalves - SPF & 1 & 3 \\
\hline Polygalaceae & M.C. Marques - RB & 3 & 14 \\
\hline Polygonaceae & G. Pedralli \& A.P.S. Gonçalves - CETEC & 2 & 3 \\
\hline Portulacaceae & A. Oliveira- HUEFS & 1 & 2 \\
\hline Proteaceae & J.R. Pirani - SPF & 1 & 1 \\
\hline Rapateaceae & M.T.V.A. Campos - SPF & 1 & 1 \\
\hline Rhamnaceae & P.T. Sano - SPF & 1 & 1 \\
\hline Rosaceae & M.C. Assis \& J.R. Pirani - SPF & 1 & 1 \\
\hline Rubiaceae & M.T.V.A. Campos \& J.R. Pirani - SPF & 24 & 42 \\
\hline Rutaceae & J.R. Pirani - SPF & 5 & 6 \\
\hline Santalaceae & D.C. Silva, M.A. Farinaccio \& R. Camacho - SPF & 1 & 1 \\
\hline Sapindaceae & M.S. Ferrucci - CTES & 7 & 14 \\
\hline Sapotaceae & L.A. Skorupa - EMBRAPA & 2 & 6 \\
\hline Scrophulariaceae & V.C. Souza - ESA & 6 & 9 \\
\hline Smilacaceae & R.P. Andreatta - RUSU & 1 & 3 \\
\hline Solanaceae & S.C. Galassi, T.R.S. Silva \& R. Mello-Silva - SPF & 4 & 9 \\
\hline Sterculiaceae & C. Cristóbal - CTES \& J.G. Saunders- TEX & 5 & 12 \\
\hline Styracaceae & A.C. Marcato \& J.R. Pirani - SPF & 1 & 1 \\
\hline Symplocaceae & A.F. Costa - R \& R.M. Takata - SPF & 1 & 1 \\
\hline Theaceae & M.C. Assis - SPF & 1 & 2 \\
\hline Tiliaceae & G.L. Esteves-SP \& M.S. Ferrucci - CTES & 2 & 2 \\
\hline Trigoniaceae & M. Groppo Jr. - SPF & 1 & 1 \\
\hline Turneraceae & M.M. Arbo - CTES & 2 & 8 \\
\hline Ulmaceae & A.F. Costa - R \& R.M. Takata - SPF & 1 & 1 \\
\hline Umbelliferae & I.P. Correa \& J. R. Pirani - SPF & 2 & 2 \\
\hline Velloziaceae & R. Mello-Silva - SPF & 2 & 18 \\
\hline Verbenaceae & F.R. Salimena - CESJ \& T.R.S. Silva - SPF & 5 & 15 \\
\hline Violaceae & J.P. Souza \& V.C. Souza - ESA & 1 & 2 \\
\hline Vitaceae & J.A. Lombardi - BHCB & 1 & 1 \\
\hline Vochysiaceae & K. Yamamoto - UEC & 3 & 10 \\
\hline Xyridaceae & M.G.L. Wanderley - SP & $1 *$ & $13^{*}$ \\
\hline TOTAL & & 467 & 107.3 \\
\hline
\end{tabular}


Os nomes de autores de táxons estão abreviados segundo as indicações de Brummitt \& Powell (1991), e as obras clássicas segundo Stafleu \& Cowan (19761988).

Ao final da publicação da flora, será apresentada uma síntese geral dos dados, incluindo análise comparativa com outras floras do Espinhaço.

\section{Riqueza florística e endemismos}

A Tabela 1 apresenta o número total de pteridófitas e as famílias de gimnospermas e angiospermas encontradas na Serra de Grão-Mogol, com o número de gêneros e espécies, como resultado desse trabalho. As pteridófitas estão representadas na região por $15 \mathrm{fa}$ mílias, as gimnospermas por apenas uma (Podocarpaceae) e as angiospermas por 113 famílias.

Embora ainda sejam estimativas preliminares os totais apresentados para 12 famílias, cujo tratamento pelo pesquisador responsável não foi concluído até o presente, pode-se avaliar um flora vascular composta de pelo menos 467 gêneros e 1073 espécies. 17 famílias estão presentes na área com 15 ou mais espécies. As famílias mais ricas em espécies são Leguminosae (104 spp.), Compositae (82 spp.), Melastomataceae (ca. 43 spp.), Rubiaceae (42 spp.), Gramineae (41 spp.), Apocynaceae s.l. (39 spp., incluindo Asclepiadoideae), Euphorbiaceae (38 spp.), Cyperaceae (ca. 34 spp.), Myrtaceae (34 spp.), Orchidaceae (30 spp), Malpighiaceae (26 spp.) e Eriocaulaceae (ca. 26 spp.).

Embora nessa flora Apocynaceae já esteja sendo tratada em sua nova circunscrição (englobando as tradicionais Asclepiadaceae como subfamília, v. Judd et al. 1999), não foi possível adotar Malvaceae sensu lato (i.e. englobando também as Bombacaceae, Sterculiaceae e Tiliaceae tradicionais, v. Judd \& Machester 1997, Judd et al. 1999, Bayer et al. 1999), porque 3 monografias das famílias tradicionais envolvidas já estavam concluídas antes da emergência da nova circunscrição desse grupo. Considerando-se Malvaceae s.l. o grupo somaria 32 espécies e passaria a aparecer entre as famílias mais ricas, logo abaixo de Cyperaceae e Myrtaceae.

Entre os gêneros particularmente ricos, estão representados na área por 10 ou mais espécies os seguintes: Chamaecrista (20 spp), Vellozia (18 spp.), Paepalanthus (14 spp), Xyris(ca. 13 spp), Miconia (12 spp), Croton(11 spp.), Mimosa (11 spp.), Eugenia (11 spp.) e Myrcia (10 spp.).

A alta riqueza florística, e em particular dos gêneros e famílias supra-citados, é recorrente em relação a outras áreas da Cadeia do Espinhaço com flora já bem documentada, como Serra do Cipó (1590 espécies vasculares, Giulietti et al. 1987), Serra do Ambrósio (Pirani et al. 1994), Pico das Almas (1044 espécies vasculares, Stannard 1995). Em primeira análise, a cifra total en- contrada na Serra do Cipó parece consideravelmente superior às 1065 espécies agora reportadas para GrãoMogol, porém devem ser ressaltadas as diferenças de esforço de coleta e de tamanho da área amostrada em cada serra. Uma análise comparativa mais aprofundada das listas florísticas no Espinhaço deverá ser efetuada ao final de publicação da Flora de Grão-Mogol, quando deverão também estar disponíveis os dados florísticos sobre a Serra de Catolés, Chapada Diamantina, Bahia (D.C. Zappi et al., em preparação). Nessa oportunidade, uma análise dos padrões de distribuição geográfica dos elementos dessas floras poderá ser concretizada. Entretanto, deve ser ponderado desde já que tais análises comparativas devem ser trabalhadas com cautela, uma vez que no Espinhaço em Minas Gerais observa-se um progressivo decréscimo no esforço de coleta em direção ao norte, fato que pode afetar os dados disponíveis sobre ocorrência e distribuição das espécies e conduzir a interpretações distorcidas sobre centros de diversidade e endemismo (v. Rapini et al. 2002).

A região de Grão-Mogol aparentemente abriga um contingente considerável de espécies endêmicas, várias delas descritas recentemente. A maioria das 59 espécies listadas na Tabela 2 só são conhecidas das áreas próximas aos sítios de amostragem deste trabalho (Fig. 2). Outras, ali assinaladas com (*), já foram também encontradas em uma ou mais das outras serras da mesma região, notadamente Morro do Chapéu (e outras elevações de Cristália), Serra da Canastra (Botumirim), Serra de Itacambira, Serra do Calixto e Serra do Catuni. Como essas serras vizinhas são ainda muito pobremente cobertas por coletas, não se pode ter ainda certeza do grau efetivo de endemismos restritos apenas à Serra de Grão-Mogol, fato adequadamente comentado por Rapini et al. (2002). Mesmo não sendo exclusivas de Grão-Mogol, essas e outras espécies com distribuição geográfica restrita a elevações do nordeste de Minas Gerais são certamente muito relevantes para caracterizar a flora regional e reforçam a necessidade de implementação de medidas para conservação da diversidade biológica. Além disso, os dados resultantes deste e dos demais levantamentos florísticos supra-citados apontam claramente para uma sustentação em favor do reconhecimento de uma província florística ou fitocória dos campos rupestres, como proposta por Prance (1994).

\section{Conservação}

A região de Grão-Mogol e Botumirim foi eleita como área de importância biológica muito alta, e portanto área prioritária para conservação da flora de Minas Gerais, por Costa et al. (1998). Além dos aspectos paisagísticos, sustentam essa posição os numerosos en- 
Tabela 2. Espécies endêmicas da região de Grão-Mogol presentes na área estudada. As espécies marcadas com (*) são também encontradas em outras serras da mesma região, notadamente Cristália, Serra da Canastra e/ou Serra de Itacambira, Minas Gerais, Brasil.

\section{ACANTHACEAE}

Stenandrium hatschbachii Wassh.

Stenandrium stenophyllum Kameyama

APOCYNACEAE

Mandevilla sp. nov.

BROMELIACEAE

Dyckia grao-mogolensis Rauh

Encholirium iruinii L.B. Sm.

Orthophytum humile L.B. Sm.

CACTACEAE

Brasilicereus markgrafii Backeb. \& Voll. *

Discocactus horstii Buin. \& Brederoo

D. pseudoinsignis Taylor \& Zappi *

Micranthocereus auriazureus Buin. \& Brederoo COMPOSITAE

Acritopappus irvinii R.M. King \& H. Rob.

Aspilia decumbens D.J.N. Hind

Calea hatschbachii Pruski \& D.J.N. Hind

Calea semirii Pruski \& D.J.N. Hind

Mikania citriodora W.C. Holmes

M. glabra D.J.N. Hind *

M. reynoldsii W.C. Holmes

Senecio gertii Zardini

Verbesina pseudoclaussenii D.J.N. Hind

Vernonia hatschbachii (H. Rob.) D.J.N. Hind

DROSERACEAE

Drosera graomogolensis T. Silva

ERIOCAULACEAE

Paepalanthus extremensis Silveira

Paepalanthus graomogolensis Silveira

EUPHORBIACEAE

Sebastiania nummularifolia I. Cordeiro*

IRIDACEAE

Pseudotrimezia concava Ravenna *

Pseudotrimezia tenuissima Ravenna

LABIATAE

Hyptis piranii Harley

LEGUMINOSAE-CAESALPINIOIDEAE

Chamaecrista aristala (Benth.) Irwin \& Barneby

C. fodinarum Irwin \& Barneby

C. stillifera (Irwin \& Barneby) Irwin \& Barneby

C. strictifolia Irwin \& Barneby *

C. tephrosiifolia (Benth.) Irwin \& Barneby

C. ulmea Irwin \& Barneby
LEGUMINOSAE-PAPILIONOIDEAE

Harpalyce parvifolia Irwin \& Arroyo

LYTHRACEAE

Cuphea teleandra Lourteig

Diplusodon aggregatifolius T. Cavalcanti *

MALVACEAE

Abutilon monteiroi Krapov.

Pavonia graziela' Krapov.

MELASTOMATACEAE

Marcetia hatschbachii A.B. Martins

Trembleya hatschbachii Wurdack \& E. Martins *

MONIMIACEAE

Siparuna espinhacensis Jangoux

MYRTACEAE

Eugenia blanda Sobral

OCINACEAE

Ouratea hatschbachiii Yamamoto

Sauragesia elegantissima A. St.-Hil. *

ORCHIDACEAE

Encyclia duveenii Pabst

RUBIACEAE

Hindsia iruinii Steyerm. *

Staelia hatschbachii J.H. Kirkbr.

VELLOZIACEAE

Barbacenia reflexa L.B. Sm. \& Ayensu

B. riparia (N.L. Menezes \& Mello-Silva) Mello-Silva

B. umbrosa L.B. Sm. \& Ayensu*

Vellozia brachypoda L.B. Sm. \& Ayensu

$V$. bradei Schulze-Menz

V. grao-mogolensis L.B. Sm.

V. luteola Mello-Silva \& Menezes *

$V$. marcescens L.B. Sm. *

V. maxillarioides L.B. Sm. *

V. prolifera Mello-Silva

$V$. spiralis L.B. Sm.

VERBENACEAE

Lippia bradei Moldenke * 
demismos encontrados. Através de decreto de 22 de setembro de 1998 foi criado nessa área o Parque Estadual da Serra da Bocaina pelo Governo do Estado de Minas Gerais, mas as medidas para a efetiva implantação da unidade de conservação ainda estão em andamento. Vale ressaltar que as áreas protegidas pelo parque situam-se quase que exclusivamente acima da cota altitudinal de $750 \mathrm{~m}$, cobrindo áreas essencialmente rupestres e portanto afetando com baixa intensidade as atividades econômicas das populações locais.

A influência antrópica sobre os diferentes tipos de vegetação é marcante em toda a região. As matas sofrem a retirada de madeira e ação do fogo, ou são drasticamente removidas para fabricação de carvão ou para culturas como mandioca, cana-de-açúcar, arroz, feijão, milho, tomate, pimentão e pimenta. Os campos são alterados pela pastagem por gado, por queimadas, ou para pequenas culturas como a do abacaxi, e ainda pelas atividades de mineração executadas irregularmente pelos garimpeiros, que revolvem solo e cascalhos $\mathrm{em}$ vários terrenos, deixando depois áreas com subsolo ou cascalho expostos, dificilmente recolonizados pela vegetação natural. No período colonial, foram encontrados minerais preciosos na serra de Grão-Mogol, notadamente diamantes, e embora hoje em dia atividade mineradora não seja rentável, ainda é praticada esporadicamente. Pratica-se ainda o extrativismo de sempre-vivas (principalmente espécies de Syngonanthus, Eriocaulaceae) para uso em ornamentação e remoção de caules de canelas-de-ema (Vellozia spp.) para combustível. Todas essas ameaças à biodiversidade de ecossistemas da Cadeia do Espinhaço, e ainda outras, já foram apontadas e descritas por autores como Burman (1991) e Giulietti et al. (1988, 1997).

Historicamente, na região Norte de Minas Gerais coexistiram diferentes etnias indígenas que, além da caça e pesca, já praticavam a agricultura quando passaram a conviver com os colonizadores e com os escravos africanos (Dayrell 1998). Esse mesmo autor considera que do mesclar dessas diferentes inf luências culturais e do isolamento nas extensas regiões de "gerais", surgiu a agricultura geraizeira, com inegável influência da agricultura indígena. Esta se caracterizaria pela proposta sui generis de apropriação dos recursos naturais locais, destacando-se como estratégias principais a diversificação de cultivos de acordo com a diversidade fisiográfica ambiental, e o aproveitamento da vegetação nativa como complemento para subsistência (plantas como forragem para o gado, frutos para alimentação humana, para produção de sabões e óleos, plantas medicinais, madeiras para lenha, construçōes e cercas, e fibras para confecção de chapéus e vassouras). Na década de 70, teve início na região um processo de modernização, com expansão de grandes fazendas de criação extensiva de gado de corte, com substituição de pastagens nativas por gramíneas exóticas e implantação de maciços homogêneos de Eucalyptus e Pinus, para abastecimento do polo siderúrgico mineiro e para a indústria de papel e celulose. Esse processo acelerou significativamente o ritmo do desmatamento indiscriminado de remanescentes florestais e mesmo de outros tipos de cobertura vegetal nativa da região (Dayrell 1998). Dados do Instituto Estadual de Florestas (IEF 1992) apontam para redução da cobertura vegetal da região de $85 \%$ do território, em 1970 , para $32 \%$ ern 1990.

Nesse processo de desenvolvimento, também foram estimulados, no nordeste de Minas Gerais, a implantação de grandes projetos de irrigação públicos e privados e produção de frutos diversos (como uva, manga, banana, pepino) para abastecimento dos grandes centros do sudeste ou para exportação.

Embora todo esse processo tenha restringido um pouco a agricultura geraizeira tradicional, ela permanece expressiva em muitos municípios da região. Estudando quatro propriedades de agricultores tradicionais no município de Riacho dos Machados, situado a cerca de $100 \mathrm{~km}$ ao norte de Grão-Mogol, Dayrell (1998) encontrou até 65 diferentes espécies de plantas cultivadas e 137 distintas variedades agrícolas manejadas por esses agricultores. Identificou também que atividades extrativistas contribuem com até $42 \%$ da produção bruta anual do sistema produtivo, fornecendo produtos para comercialização e/ou auto-consumo. Ainda segundo o mesmo autor, entre 26 e 78 espécies diferentes de plantas nativas são manejadas com alguma freqüência por essas populações.

Hoje a região norte de Minas Gerais ainda é a mais pobre do estado, e se vê diante do desafio de configurar sistemas agrícolas sustentáveis capazes de compatibilizar crescimento econômico com conservação dos recursos naturais e promoção de melhoria social.

Os solos da região de Grão-Mogol, como de resto na maior parte da Cadeia do Espinhaço, são predominantemente rasos, ácidos e pobres em nutrientes e matéria orgânica. Seu potencial para uso em práticas agrícolas expressivas é muito limitado, e a possibilidade de atividade de mineração bem sucedida é remota. Por outro lado, essa serra, como uma "ilha" instalada em meio à região transicional entre os domínios do cerrado e da caatinga, abriga uma vegetação heterogênea, cuja flora peculiar e muito diversificada abriga elevado grau de endemismo (Tabela 2). Williams \& Humphries (1994) ressaltaram que endemismos não representam uma medida efetiva da biodiversidade mas de amplitude de distribuição dos táxons, e que por isso não constituiriam os indicadores ideais para seleção de áreas para conservação. Contudo, na região de Grão- 
Mogol, a maioria dos elementos da flora são ainda pouco conhecidos nos aspectos biológicos básicos e sua conservação deve ser garantida, pois além da simples necessidade de preservação de patrimônio genético, essa flora abarca vários exemplos de plantas já empregadas para diversos fins pela população local, ao lado de numerosos outros com alto potencial ornamental e paisagístico, medicinal e como fornecedoras de fibras. Alternativas para o desenvolvimento sustentado da região poderão envolver ainda a implementação de infra-estrutura turística, aproveitando a grande beleza cênica da área e seu patrimônio ambiental, histórico e cultural.

\section{Agradecimentos}

Os autores expressam sinceros agradecimentos a todos os pesquisadores que colaboraram nas coletas e nas identificações dos espécimes, e na redação dos trabalhos sobre cada família, assim como às institutições a que eles pertencem. Desde o início do projeto, foi de especial relevância o apoio da Dra Nanuza Luiza de Menezes, grande entusiasta e empreendedora de pesquisas nos campos rupestres. À Dra Marico Meguro somos gratos pelo apoio em várias expediçòes a serras do Espinhaço, em particular nas duas viagens a GrãoMogol em que nos prestou ajuda inestimável na caracterização geral da vegetação da área. Numa primeira etapa dos trabalhos, a atuação da bióloga Marta Camargo de Assis no processamento e distribuição dos espécimes aos especialistas foi marcante para o bom andamento do projeto. Na longa etapa de estudo das famílias, destaca-se a dedicação de numerosos alunos de pós-graduação que, durante as disciplinas dos Profs. Ana Maria Giulietti e José Rubens Pirani, realizaram os estudos de vários gêneros e famílias para as quais não havia especialista disponível. Destacamos nesse aspecto a atuação da Dra Inês Cordeiro e do Dr. Luciano Paganucci de Queiroz, que corrigiram e reestruturaram os trabalhos parciais dos gêneros de Euphorbiaceae e Leguminosae executados por três turmas de alunos. Menção particular deve ser feita ao mestrado de Renato de Mello-Silva, realizado entre 1985 a 1989, sobre Velloziaceae de Grão-Mogol, cuja atividade de campo, regular e abrangente para todas as plantas vasculares, contribuiu grandemente para o levantamento dessa flora. Alguns dos trabalhos sobre famílias menores foram também executados por estudantes de Iniciação Científica e Aperfeiçoamento, cujo entusiasmo sempre foi por nós muito apreciado.

Durante a fase de expedições de coleta em GrãoMogol, a hospitalidade da Pensão de Dona Dora e posteriormente do Sr. Virgílio Colares, do Hotel e Restaurante Beira Rio, foi sempre apreciada. Agrade- cimentos também são devidos ao Sr. Geraldo Ramos Fróes, por seu apoio fornecendo informações sobre trajetos e áreas especiais, e por facilitar nosso contato com os técnicos do Instituto Estadual de Florestas de Minas Gerais, em Montes Claros, quando dos trabalhos para a implementação do Parque Estadual da Serra da Bocaina. Agradecem ainda ao Sr. Rivaldo Andrade, que franqueou a entrada em suas terras (Fazenda Matão) com imensos monjoleiros, paus d'óleo, perobas e jatobás, à beira do rio Itacambiruçu, e aos rapazes de fazendas locais, principalmente do Jambeiro, que nos guiaram em trajetos pelo alto da serra.

Os recursos e bolsas fornecidos pelo Conselho de Desenvolvimento Científico e Tecnológico (CNPq), World Wildlife Fund (WWF) e Fundação de Amparo à Pesquisa do Estado de São Paulo (FAPESP) viabilizaram esse projeto. $\mathrm{O}$ apoio logístico irrestrito do Instituto de Biociências da USP, através de estrutura laboratorial, veículos, motoristas, secretários e técnicos, garantiu o sucesso da maior parte dos trabalhos desse projeto, do campo à redação final.

O traçado artístico de Emiko Naruto permeia a grande maioria das ilustrações dos trabalhos; em trabalhos concluídos mais recentemente, aparece também a contribuição valiosa do desenhista Rogério Lupo.

O auxílio do Dr. Alessandro Rapini na formatação e padronização dos textos da maioria das famílias foi vital para viabilizar adequadamente a fase de composição gráfíca. Amauri César Marcato prestou auxílio inestimável no preparo das figuras basedas em fotografias. Dr. Márcio R. Martins gentilmente forneceu equipamento e auxílio no preparo de imagens eletrônicas baseadas em fotografias, constantes deste artigo introdutório.

\section{Referências}

ABREU, A.A. 1984. O planalto de Diamantina: um setor da Serra do Espinhaço em Minas Gerais. (rienlação - Instituto de Geografia, USP, 5: 75-79.

BARROSO, G.M. 1956. Espécies novas do Herbário do Jardim Botânico do Rio de Janciro. Arq. Jard. Bol. Rio de Janeiro 14: 257. 266.

BAYER, C., FAY, M.F., BRUIJN, A.Y., SAVOLAINEN, V., MORTON, C.M., KUBITZKI, K., ALVERSON, W.S. \& CHASE, M.W. 1999 Support for an expanded family concept of Malvaceae within a recircumscribed order Malvales: a combined analysis of plastid alpB and $r, \mathrm{~L}$ DNA sequences. Bol. J. Linn. Soc. 129: 267-303.

BITTRICH, V. 1996. Três novas espécies do gênero Clusia (Guttiferae) do Brasil. Bol. Bol. Univ. S'äo P'aulo 15: 73-82.

BORBA, E.L., SEMIR, J. \& BARROS, F. 1998. Bulbophyllum involulum Borba, Semir \& Barros (Orchidaceae), a new species from the Brazilian "campos rupestres". Non'on 8(3): 225-229.

BRANDÃO, M. 1992. Caracterizaçāo geomorfológica, climática, florística e faunística da Serra do Curral em Belo Horizonte, MG. Daphne 2: 5-12.

BRANDĀO, M., GAVILANES, M.L., ARAUJO, M.G. \& LACABUENDIA, J.P. 1995. Município de Diamantina, MG I - cober- 
tura vegetal e composiçāo florística de suas formaçōes. Daphlne $5(4): 28-52$.

BRANDÃO, M., GAVILANES, M.L., LACA-BUENDIA, J.P., CUNHA, L.H. \& MACEDO, J.F. 1989. Flora da Serra do Itabirito, Minas Gerais - primeira contribuição. Ac:la bol. Brasil. 3(supl.): 237-251.

BRANDÃO, M., GAVILANES, M.L., LACA-BUENDIA, J.P., MACEDO, J.F. \& CUNHA, L.H. 1991. Contribuição para o conhecimento da vegetação da Cadeia do Espinhaço em Minas Gerais (Serra do Itabirito) - III. Daphne 3: 39-41.

BRANDÃO, M. \& SILVA FILHO, P.V. 1992. Os campos rupestres no município de Barāo de Cocais - MG. Daphlıne 3(2): 11-20.

BRUMMITT, R.K. \& POWELL, C.E. 1992. Authors of plant names. Royal Botanic Gardens. Kew.

BURMAN, A. 1991. Saving Brazil's savannas. New Scienlist 1758: 3034.

CABRERA, A.L. \& WILLINK, A. 1973. Biogreografia de A merica Latina. Secretaria General de la Organización de los Estados Anericanos. Washington.

CAVALCANTI, T.B. 1989. Cuphea rubro-virens T. Cav., nova espécie de Minas Gerais, Brasil e nota sobre (. Ieleandra Lourt. Bol. Bol. Univ. Sä̃o P'aulo 11: 71-76.

CAVALCANTI, T.B. 1998. New species of Diplusodon (Lythraceae) from Brazil. Novon 8(4): 337-351.

CORDEIRO, I. 1989. Sebastiania nummularifolia I. Cord. (Euphorbiaceae), nova espécie dos campos rupestres de Minas Gerais, Brasil. Bol. Bol. Univ. Säo Paulo 11: 77-80.

COSTA, C.M.R., HERRMANN, G., MARTINS, C.S., LINS, L.V. \& LAMAS, I.R. (orgs.) 1998. Biodiversidade em Minas Gerais. Um allas para sua comservação. Fundação Biodiversitas. Belo Horizonte.

CRONQUIST, A. 1981. An inlegraled system of classification of flowering planls. Columbia University Press. New York.

DAYRELL, C.A. 1998. Geraizeiros e biodiversidade no Norle de Minas Gerais: a contribuis:ão da agroecologia e da elnoecologia nos esludos dos agroecossistemas tradicionais. Universidade Internacional de Andalucia. Espanha.

DERBY, O.A. 1906. The Serra do Espinhaço, Brazil.J. Geol. 14: 374401.

EITEN, G. 1983. Classifiraşão da vegrelação do Brasil. CNPq. Brasília.

EITEN, G. 1990. Vegetação do cerrado. In M.N. Pinto (org.) Cerrado. Caracterizascão, ocupação e persperclivas. Editora Universidade de Brasília. Brasília.

FERREIRA, M.B., D'ASSUNÇÃO, W.R.C. \& MAGALHÃES, G.M. 1978. Nova contribuição para o conhecimento da vegetação da Cadeia do Espinhaço ou Serra Geral (Maciço do Caraça). (rúa des 6: 49-66.

FERREIRA, M.B. \& MAGALHÃES, G.M. 1977. Contribuição para o conhecimento da vegetação da Serra do Espinhaço em Minas Gerais (Serras do Grão-Mogol e da Ibitipoca). In Anais XXVI Congresso Nacional de Bolânic:s. Academia Brasileira de Ciências. Rio de Janeiro, p. 189-202.

GIULIETTI, A.M., MENEZES, N.L., PIRANI, J.R., MEGURO, M. \& WANDERLEY, M.C.L. 1987. Flora da Serra do Cipó, Minas Gerais: caracterização e lista das espécies. Bol. Bol. Univ. São l'aulo 9: 1-151.

GIULIETTI, A.M., GIULIETTI, N., PIRANI, J.R. \& MENEZES, N.L. 1988. Estudos em sempre-vivas: importância econômica do extrativismo em Minas Gerais, Brasil. Ar:ı Bol. Brasil. 1(2) (supl.): 179-193.

GIULIETTI, A.M. \& PIRANI, J.R. 1988. Patterns of geographic distribution of some plant species from the Espinhaço Range, Minas Gerais and Bahia. In P.E. Vanzolini \& W.R. Heyer (eds.) Proceedings of a workshop on neotropical distribution pallerns held 12 I6 January 1987. Academia Brasileira de Ciências. Rio de Janeiro, p. 39-69.
GIULIETTI, A. M., PIRANI, J. R. \& HARLEY, R. M. 1997. Espinhaço Range. In S. D. Davis, V. H. Heywood, O. Herrera-MacBryde \& J. Villa-Lobos (eds.) Centres of planl diversily. Vol. 3. The Americas. National Museum of Natural History, Smithsonian Institution. Washington, p. 397-404.

GLAZIOU, A.F.M. 1905. Plantae Brasiliae Centralis a Glaziou lectae. Mém. Soc. Bol. France 3: 1-296.

GUEDES, M.L.S. \& ORGE, M.D.R. 1998. Checklist das espécies vasculares do Morro do Pai Inácio (Palmeiras e Serra da Chaptadinha (Len(:ois), Chapada Diamanlina, Bahia, Brasil. Universidade Federal da Bahia. Salvardor.

HARLEY, R.M. 1995. Introdução. In B.L. Stannard (ed.) Florc of the Pico das Almas, Chapada Diamantina, Bahia, Brazil. Royal Botanic Gardens. Kew, p. 1-78.

HARLEY, R.M. \& SIMMONS, N.A. 1986. Florula of Mucugê, Chapada Diamantina, Bahia, Brazil. Royal Botanic Gardens. Kew.

HIND, D.J.N. 1994. New Compositae from the Serra do Grão-Mogol (Mun. Grão-Mogol, Minas Gerais, Brazil) and the surrounding area. Kew Bull. 49(3): 511-522.

HOLMGREN, P.K., HOLMGREN, N.H. \& BARNETT, L.C. 1990. Index Herbarionum. Parl I: the herbaria of the world. Ed. 8. New York Botanical Garden. New York.

JOLY, A.B. 1970. Conhesa a vegetaşāo brasileira. EDUSP, Polígono. São Paulo.

JUDD, W.S., CAMPBELL, C.S., KELLOG, E.A. \& STEVENS, P.F. 1999. Planl systemalics. A phylogenetic approach. Sinauer Associates. Sunderland.

JUDD, W.S. \& MANCHESTER, S.R. 1997. Circumscription of Malvaceae (Malvales) as determined by a preliminary cladistic analysis of morphological, anatomical, palynological, and chemical characters. Brillonia 49(3): 384-405.

KAMEYAMA, C. 1996. A new species of Stenandrium (Acanthaceae) from Grão-Mogol, Minas Gerais, Brazil. Novon 6: 268-270.

KING, L.C.1956. A geomorfologia do Brasil. Revisla brasil. Geogr. 18: $147-265$.

KIRKBRIDE, J.H. 1997. Manipulus rubiacearum - VI. Brittonia 49(3): 354-379.

LOHMANN, L.G. \& PIRANI, J.R. 1996. Tecomeae (Bignoniaceae) da Cadeia do Espinhaço, Minas Gerais e Bahia, Brasil. Ac:la Bot. Brasilica 10(1): 103-138.

LOURTEIG, A. 1987. Lythraceae Austroamericanae. Addenda et corrigenda II. Sellowia 39: 5-48.

MAGALHÃES, G.M. 1954. Contribuição para o conhecimento da flora dos campos alpinos de Minas Gerais. In A.R. Schultz (ed.) Anais V Congressso Nacional de Botânica. Sociedade Botânica do Brasil. Porto Alegre, p. 227-304.

MAGALHÃES, G.M. 1966. Sobre os cerrados de Minas Gerais. An. Ac:ad. Bras. (ïênnc: 38 (supl.): 59-70.

MARKGRAF, F. 1940. Neue Pflanzenarten aus Brasilien. Notizblatl 15: 214-221.

MARTINS, A.B. 1995. Marcetia halschluarhii (Melastomataceae Microlicieae): uma nova espécie de Grão-Mogol, Minas Gerais, Brasil. Bol. Bol. Uniu. Säo l'aulo 14: 43-47.

MARTINS, E. 1995. Nova espécie do gênero Trembleya DC. (Microlicieae - Melastomataceae). Bol. Bol. Univ. São P'aulo 14: 3942.

MEGURO, M., PIRANI, J.R., GIULIETTI, A.M. \& MELLO-SILVA, R. 1994. Phytophysiognomy and composition of the vegetation of Serra do Ambrósio, Minas Gerais, Brazil. Revista Bras. Bot. 17(2): 148-166.

MEGURO, M., PIRANI, J.R., MELLO-SILVA, R. \& GIULIETTI, A.M. 1996a. Estabelecimento de matas ripárias e capões nos ecossistemas campestres da Cadeia do Espinhaço, Minas Gerais. Bol. Bol. Univ. Säo l'aulo 15: 1-11.

MEGURO, M., PIRANI, J.R., MELLO-SILVA, R. \& GIULIETTI, A.M. 1996b. Caracterização florística e estrutural de matas ripárias e 
capões de altitude da Serra do Cipó, Minas Gerais. Bol. Bol. Univ. São I'aulo 15: 13-29.

MELLO-SILVA, R.M. 1991. A new species of Vellozia from the Espinhaço Range, Brazil, with some considerations on the section Xerophyloides. Kew Bull. 46(2): 321-326.

MELLO-SILVA, R. 1995. Aspectos taxonômicos, biogeográficos, morfológicos e biológicos das Velloziaceae de Grão-Mogol, Minas Gerais, Brasil. Bol. Bot. Univ. Sĩo Paulo 14: 49-79.

MELLO-SILVA, R. \& MENEZES, N.L. 1988. Duas espécies novas de Velloziaceae de Minas Gerais. Acka bol. Bras. 1 (supl.): 195207.

MOREIRA, A.A.N. 1977. Relevo. In IBGE (ed.) Geografia do Brasil. Regriño-Nordeste. vol. 2. IBGE. Rio de Janeiro, p. 145 .

MOREIRA, A.A.N. \& CAMELIER, C. 1977. Relevo. In IBGE (ed.) Geo-grafia do Brasil. Regiño Sudesle. vol. 3. IBGE. Rio de Janeiro, p. $1-50$.

NIMER, E. 1977. Clima. In IBGE (ed.) Geografia do Brasil. Regiño Sulleste. vol. 3. IBGE. Rio de Janeiro, p. 51-89.

PERON, M.V. 1989. Listagem preliminar da flora fanerogâmica dos campos rupestres do Parque Estadual do Itacolomi - Ouro Preto/Mariana, MG. Rodriguésia 67(41): 63-69.

PIRANI, J.R., GIULIETTI, A.M., MELLO-SILVA, R. \& MEGURO, M. 1994. Checklist and patterns of geographic distribution of the vegetation of Serra do Ambrósio, Minas Gerais, Brazil. Revista Bras. Bol. 17(2): 133-147.

PRANCE, G.T. 1994. The use of phytogeographic data for conservation planning. In P.I. Forey, C.J. Humphries \& R.I. Vane-Wright (eds.) Systematios and conservation evaluation. Clarendon Press. Oxford, p. 145-163.

PRUSKI, J.F. \& HIND, D.J.N. 1998. Two new species of Calea (Com- positae: Heliantheae) from Serra do Grão-Mogol and vicinity, Minas Gerais, Brazil. Kew Bull. 53(3): 695-701.

RAPINI, A., MELLO-SILVA, R. \& KAWASAKI, M.L. 2002. Richness and endemism in Asclepiadoideae (Apocynaceae) from the Espinhaço Range of Minas Gerais, Brazil - a conservationist view. Biodiv. Cons. 11(10): 1733-1746.

RENGER, F.E. 1979. Evolução dos conceitos geológicos da Serra do Espinhaço. Alas do $I^{\circ}$ Simpósio de Geologia de Minas Gerais. Diamantina, p. 9-27.

SAINT-HILAIRE, A.F.C.P. 1837. Tableau géographique de la véggélalion primilive dans la Province de Minas Gerais. Ed. 2. A. Pihan de la Forest. Paris.

SOBRAL, M. 1993. Eugrenia blanda (Myrtaceae), nova espécie de Minas Gerais, Brasil. Bradea 6(26): 234-236.

STAFLEU, F.A. \& COWAN, R.S. 1976-1988. Taxonomic lileralure. Ed. 2. Bohn, Scheltema \& Holkema. Utrecht. 7 vols.

STANNARD, B.L. (ed.) 1995. Flora of the Pico das Almas, Chapada Diamanlina, Ballia, Brazil. Royal Botanic Gardens. Kew.

VELOSO, H.P., RANGEL FILHO, A.L.R. \& LIMA, J.C.A. 1991. Classificascão da vegyelaşão brasileira, adlaptada a um sistema universal. IBGE. Rio de Janeiro.

YAMAMOTO, K. 1995. Ouralea halschbachii(Ochnaceae) - una nova espécie de Grão-Mogol, Estado de Minas Gerais, Brasil. Bol. Bol. Univ. Säo P'anlo 14: 33-37.

WALLNÖFER, B. 1999. Neue Diospyros-Arten (Ebenaceae) aus Südamerika. Ann. Nalurhist. Mus. Wien 101B: 565-592.

WILLIAMS, P.H. \& HUMPHRIES, C.J. 1994. Biodiversity, taxonomic relatedness, and endemism in conservation. In P.I. Forey, C.J. Humphries \& R.I. Vane-Wright (eds.) Systematics and conservalion evaluation. Clarendon Press. Oxford, p. 269-287.

\section{Apêndice 1. Relação de expedições a Grão-Mogol, Minas Gerais, Brasil, com dados sobre datas, coletores, localidades visitadas e hábitats.}

Expedição 1. 11 - 17.IV.1981 - CFC:R 696-1029

Col. A. Furlan, I. Cordeiro, J.R. Pirani, L. Rossi, M.C.E. Amaral \& N.L. Menezes.

CFCR 696 - 707 - Estrada para Francisco Sá, 15 km de Grão-Mogol

CFCR 708 - 734 - Margens do córrego Santo Antônio.

CFCR 735 - 849 - Próximo a Grão-Mogol - campo rupestre.

(FCR 850 - 854 - Estrada para Virgem da Lapa - mata mesófila.

CFCR $855-874-5 \mathrm{~km}$ de Grão-Mogol - campo rupestre com muita areia, próximo ao rio Itacambiruçu.

CFCR 875 - 882 - Estrada para Francisco Sá, 15 km de Grão-Mogol. CFCR 883 - 897 - Estrada para Virgem da Lapa - orla de mata.

CFCR 898 - 970 - Estrada para Cristália.

CFCR 971 - 1005 - Estrada para Virgem da Lapa - margem do rio Ventania.

CFCR 10)6 - 1029 - Estrada para Francisco Sá - cerrado à beira da estrada.

Expedição 2. 20 - 24.V.1982 - CFCR 3386-357I

Col. A.M.Giulietti, M.C.H. Manede, N.C. Hensold \& N. Giulietti. CFCK 3386 - 3416 - campo rupestre a sudoeste da cidade (ca $1 \mathrm{~km}$ ), $16^{\circ} 33^{\prime} \mathrm{S}, 42^{\circ} 53^{\prime} \mathrm{W}$.

CFCR 3417 - 350)3 - campo rupestre en direção nordeste da cidade, 16" 32's, 42" $55^{\prime \prime} \mathrm{W}$.

(FFCR 35()4 - 3524 - Estrada para Francisco Sá - direção Sudoeste campo sujo, 16" 35'S, 42" 53'W.

CFCR 3525 - 3571 - Próximo à ponte sobre o Ribeirão das Mortes, beira do rio.
Expedição 3. 26.II - 1.III.1983 - CFCRR 4081-4156

Col. I. Cordeiro \& E. Simonis.

CFC CR 4081 - 4156 - Arredores de Grão-Mogol - campos rupestres e carrascos.

Expedição 4. 25 - 27.XI.1984 - CFCR 6473-6531

Col. R.M. Harley, B.L. Stannard, J.D.P. Oliveira \& M.L. Kawasaki.

CIC CR $6473-6475-80 \mathrm{~km}$ de Francisco Sá na estrada para GrãoMogol, perto do rio Extrema - cerrado.

CFCR 6476 - 6531 - A norte de Grão-Mogol, 900-1000 m s.m. rochas quartzíticas.

Expedição 5. 2 - 7.IX.1985 - CIFCR 8296-8550

Col. J.R. Pirani, R. Mello-Silva, T.B. Cavalcanti, D.C. Zappi \& M.L. Kawasaki.

CFCR $8296-8336$ - Ribeirão das Mortes.

CFCIR 8337 - 8408 - Vale do rio Itacambiruçu, próximo à ponte da estrada de Cristália.

CF(CR 8409 - $\$ 465$ - Vale do rio Itacambiruçu, $5 \mathrm{~km}$ da cidade.

CFCR 8466 - 8550) - Fazenda Jambeiro, 7 km de Grão-Mogol.

Expedição 6. 4 - 8.1.1986 - CKCKR 8837 - 9(159

Col. J.R. Pirani, R. Mello-Silva, C. Kameyama, I. Cordeiro \& M. Meguro.

CFCR 8837 - 8853 - Margens do córrego Escurona.

CFCK 8854 - 8878 - Fazenda Jambeiro, margens da estrada até o rio Itacambiruçu. 
CFCR \$879 - 8880 - Mata ciliar do córrego Jambeiro.

CFCR 8881 - Fazenda Jambeiro, margem do rio Itacambiruçu.

CFCR 8882 - 8886 - Mata ciliar do córrego Jambeiro.

CFCR 8887 - 8930) - Cristália, Morro do Chapéu, ca. 1200 m s.r.. campo rupestre.

CFCR 8931 - 8938 - Cristália, Morro do Chapéu, ca. 1000 m s.m. mata.

CFCR 8939 - 8971 - Cristália, Morro do Chapéu - campo sujo.

CFCR 8972 - 8978 - Próximo à ponte sobre o rio Itacambiruçu, na estrada para Cristália - campo rupestre.

CFCR 8979 - 8980 - Cristália, Morro do Chapéu, ca. 1100 m s.m. campo rupestre.

CFCR 8981 - 9059 - Próximo à cidade, na estrada para Francisco Sá até a mata do topo.

Expedição 7. 23 - 27.II.1986 - CFCRR 9576-9710)

Col. R.Mello-Silva, N.L. Menezes, J.Semir, T.B. Cavalcanti \& N.S. Chukr.

CWCR 9576 - 9665 - Próximo à cidade, a leste, seguindo riacho temporário (Ribeirão dos Bois), 900-1000 m s.m.

CFCR 9667 - 9671 - Estrada para o rio Ventania - cerrado.

CFCR 9672 - Próximo ao Ribeirão das Mortes.

C.FCR 9673 - 9708 - Vale do rio Itacambiruçu, próximo à estrada para Cristália.

CFCR 97(09 - 9710 - Estrada para Cristália.

Expedição 8. 22 - 27.VII.1986 - CFCR 9805 - 9956

Col. A.M. Giulietti, R. Mello-Silva, D.C. Zappi, M. Meguro, J.C.C. Gonçalves \& N. Giulietti.

CFCR 9895 - 9874 - Córrego Escurinha - cerrado e afloramentos rochosos.

CFCR 9875 - 9879 - Vale do Itacambiruçu - próximo à ponte para Cristália.

CFCR 9880 - 9946 - Vale do Ribeirão das Mortes, subindo encosta, 850-1000 $\mathrm{m}$ alt.

CFCR 9947 - 9956 - Próximo à cidade, a leste, seguindo rio temporário ca. $700 \mathrm{~m}$ alt., Ribeirāo dos Bois.

Expedição 9. 2 - 6.IX.1986 - CFGR 9993 - 10180

CFCR 9993 - 10157 - col. I. Cordeiro \& R. Mello-Silva.

CFCR 10158-10180 - col. N.L. Menezes, T.B. Cavalcanti, I. Cordeiro \& R. Mello-Silva.

CFCR 9993 - 10026 - Ribeirão dos Bois.

CFCR lO()27 - lO()40) - Nascentes do córrego Taiobeiras.

CFCR 10041 - 10081 - Vale do riacho Ribeirão.

CFCR 10012 - 101199 - Vale do Ribeirão clas Mortes.

CFC:R I()120 - 10138 - Vale do rio Itacambiruçu, da ponte de Cristália em direção à jusante.

CFCR 10139 - 10140 - Estrada p. Francisco Sá, próximo ao Ribeirão das Mortes

CFCR $1(1) 141$ - 10157 - Torre de TV - carrascal.

CFCK $1(1) 158$ - 10173 - Torre de TV, mata montana.

CICR $10174-10178$ - Torre de TV, carrascal.

CFCR 10179 - Margens do rio Itacambiruçu.

CFCR IOISO - Ribeirão dos Bois.

Expedição 10. 19 - 26.V.1987 - CFC:R 10746 - 108999

Col. R. Mello-Silva \& J.R. Pirani.

CWCK 10746 - I0768 - Vale do Riacho Ribeirão.

CFCR $1(1769$ - 10794 - Escarpas à direita do Riacho Ribeirão, 960$1000 \mathrm{~m}$ alt.

(FC:R 10795 - I0811 - Vale do Ribeirão dos Bois, 820m-960 m alt. CFC:R I0812 - 101847 - Vale do Ribeirão das Mortes, $900 \mathrm{~m}-1100 \mathrm{~m}$ alt. CFC:R 10\$48 - 10858 - Bacia do Ribeirão das Mortes, 1100-1150 m alt. CFCR I0859 - 10884 - Vale do riacho Ribeirão, $900 \mathrm{~m}$ alt.
CFCIR 10885 - 10899 - Vale do Ribeirão das Mortes, $950 \mathrm{~m}$ alt.

Expedição 11. 1 - 7.XI.1987 - CFCR 11315 - 11616

Col. J.R. Pirani, R. Mello-Silva, I. Cordeiro \& M.C. Assis.

CFCR 11315 - 11331 - Córrego Escurona, 16³5’42"S, 4257’48"W próximo à estrada em direção a montante, 750 - $800 \mathrm{~m}$ alt.

CFCK 11332 - 11356 - Bacia do córrego Escurona - Cerrado, $16^{\circ} 35^{\prime} 42^{\prime \prime S}, 42^{\circ} 57^{\prime} 48^{\prime \prime} \mathrm{W}, 750-800 \mathrm{~m}$ alt.

CFCR 11357 - 11361 - Bacia do córrego Escurona - Encosta de afloramento rochoso $16^{\prime \prime} 35^{\prime} 42^{\prime \prime} \mathrm{S}, 42^{\circ} 57^{\prime} 48^{\prime \prime} \mathrm{W}, 800 \mathrm{~m}$ alt.

CFCR 11362 - 11373 - Bacia do córrego Escurona, 16“35'42"S, $42^{\circ} 57^{\prime} 48^{\prime \prime} \mathrm{W}, 800 \mathrm{~m}$ alt. - campo arenoso, à base de encosta rochosa.

CFCR 11374 - 11381 - Bacia do córrego Escurona, 16"35'42"S, $42^{\prime \prime} 57^{\prime} 48^{\prime \prime} \mathrm{W}, 750$ - $800 \mathrm{~m}$ alt. - cerrado.

CFCK 11382 - 11427 - Montanha à esquerda do riacho Ribeirão, Trilha da Tropa, 16³3'S, 4254' W, 850 - $1000 \mathrm{~m}$ alt.

CFCR 1142 - 11452 - Montanha à esquerda do riacho Ribeirão,

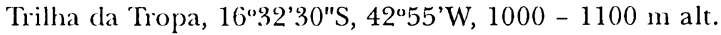

CFCR 11453 - 11468 - Montanha à esquerda do riacho Ribeirão, Trilha da Tropa, 16"32'30"S, 42"55' W, 1100-1150 m alt. - campo rupestre.

CFCK 11469 - 11489 - Bacia do Ribeirão da Morte, 16"34'S, $42^{\circ} 54^{\prime} 30^{\prime \prime} \mathrm{W}, 900-1000 \mathrm{~m}$ alt.

CFC:R 11490 - 11515 - Bacia do Ribeirão da Morte, 16"33'30"S, $42^{\prime \prime} 55^{\prime} \mathrm{W}, 1000$ - $1150 \mathrm{~m}$ alt.

CFCR 11516 - 11519 - Bacia do Ribeirāo da Morte, 16"34'S, $42^{\circ} 54^{\prime} 30^{\prime \prime} \mathrm{W}, 900-1000 \mathrm{~m}$ alt.

CFC:R 11520 - 11532a - Bacia do Ribeirão da Morte, 16"34'S, $42^{\prime \prime 5} 4^{\prime} 30^{\prime \prime} \mathrm{W}, 900 \mathrm{~m}$ alt. - carrascal denso.

CHCKR 11533 - 11534 - Bacia do Ribeirão da Morte, 16"33'30"S, $42^{\circ} 55^{\prime} \mathrm{W}, 1000-1150 \mathrm{~m}$ alt.

CFCiR 11535 - 11574 - Mata próxima ao campo de aviação, $16^{\circ} 33^{\prime} 18^{\prime \prime} \mathrm{S}, 42^{\circ} 52^{\prime} 30^{\prime \prime} \mathrm{W}, 1000 \mathrm{~m}$ alt.

CFCR 11575 - 11579 - Ribeirão dos Bois, 16"3.'36"S, 42"53'18"W, $850 \mathrm{~m}$ alt.

CFC:R 11580 - 11616 - Vale do rio Itacambiruçu, $300 \mathrm{~m}$ à jusante da foz do Córrego da Bonita, 16³5’48"S, 42"54’36"W.

Expedição 12. 24 - 31.V.1988 - CFCR 11938 - 12110

Col. D.C. Zappi, J. Prado, A. Bidá, R. Queiroz \& R. Barreto.

CFCR 11938 - 11968 - Córrego Escurona, próximo à estrada, 16³5’S, $42^{\circ} 57^{\prime} \mathrm{W}, 750-800 \mathrm{~m}$ alt.

CFCKR 11969 - 12016 - Subida da Trilha da Tropa, à esquerda do

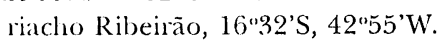

CFCKR 12017 - 12040) - Margem direita do rio Itacambiruçu entre a ponte para Cristália e a Fazenda Jambeiro, 16"35’ $\mathrm{S}, 42^{\circ} 54^{\prime} \mathrm{W}$, $650 \mathrm{~m}$ alt.

CF(KR I204I - 12047 - Margem direita do rio Itacambiruçu, entre a ponte para Cristália e a Fazenda Jambeiro, 16"35'S, 42"54'W', encosta da Serra das Cabras, 700 - $750 \mathrm{~m}$ alt.

CFCK I2048 - I2057 - Margem direita do rio Itacambiruçu, entre a ponte para Cristália e a Fazenda Jambeiro, 16“35'S, 42`54'W, $650 \mathrm{~m}$ alt. - carrasco.

CFCR 12058 - 12072 - Mata próxima ao campo de aviação, 16³3'S, $42^{\circ} 52^{\prime} \mathrm{W}, 1000 \mathrm{~m}$ alt. - solo de canga.

CFCR 12073 - 12095 - Córrego da Bonita, 16"35'S, 42"54’ W, $700 \mathrm{~m}$ alt. - carrascal.

CWCR 12096 - 12110 - Córrego Escurinha, 16"35’S, 42"57’ W, 750m alt. - campo arenoso.

Expedição 13. 14 - 16.X.1988 - Harley et al. 250(1)4-25128

Col. R.M. Harley, A.M. Giulietti, B.L. Stannard, D.J.N. Hind, C. Kameyama, J. Prado, P. Rudall, R. Simão, N. Taylor \& D.C. Zappi 
Harley el al. 250(1) - 25068 - Estrada para Francisco Sá, direção S da cidade, $16^{\circ} 37^{\prime} \mathrm{S}, 42^{\circ} 56^{\prime} \mathrm{W}, 700-850 \mathrm{~m}$ alt. - campo rupestre-cerrado.

25069 - 25128 - Estrada para Francisco Sá, $5-15 \mathrm{~km}$ ao $\mathrm{N}$ da cidade, $16^{\circ} 32^{\prime} \mathrm{S}, 42^{\circ} 47^{\prime} \mathrm{W}$, ca. $1050 \mathrm{~m}$ alt. - campo rupestre, solo arenoso e afloramento quartzítico.

Expedição 14. 8 - 14.XII.1989 - CFCR 12348 - 12745

Col. J.R. Pirani, P.T. Sano, T.R.S. Silva \& A. Freire-Fierro.

CFCR 12348 - 12432 - Vale do rio Itacambiruçu, ao longo da estrada para Cristália, 16"36'S, 42"55'W, $750 \mathrm{~m}$ alt. - carrascal: vegetação densa de arbustos e arvoretas ramosos, em solo arenoso com af loramentos rochosos.

CFCR 12433 - 12528 - Trilha da Tropa, no alto da Serra, 1000-1200 in alt. - campo rupestre.

CFCR 12529 - 12635 - Vale do rio Itacambiruçu 16"36'S, 42"55'W, $650 \mathrm{~m}$ alt. - solo arenoso-fino, com rochas, com cerrado e vegetação da margem do rio.

CFCR I2636 - 12745 - Estrada para o rio Ventania, 16"32'S, 42"49'W, $950 \mathrm{~m}$ alt. - cerrado.

Expedição 15. 11 - 18.VI.1990 - CFCR 128'14 - 13197

Col. J.R. Pirani, D.C. Zappi, R. Simão-Bianchini, A.A. Oliveira \& S. Vanin.

CFCR 12814 - 12901 - Vale do córrego Escurona, 16³6'S, 4258'W, $750 \mathrm{~m}$ alt.

CFCR 12902 - 12976 - Vale do rio Itacambiruçu, 16"36'S, 42"55'W, $670 \mathrm{~m}$ alt. - solo arenoso fino com rochas, com cerrado, carrasco e vegetação rupícola.

CFCK 12977 - 12988 - Estrada para Cristália, a cerca de $800 \mathrm{~m}$ da ponte sobre o rio Itacambiruçu, $16^{\prime \prime} 36^{\prime} \mathrm{S}, 42^{\prime \prime} 55^{\prime} \mathrm{W}, 750 \mathrm{~m}$ alt. carrasco.

CFCR 12989 - 12990 - Estrada para Cristália, a cerca de 300m da ponte sobre o Rio Itacambiruçu, 16"36'S, $42^{\prime \prime} 55^{\prime} \mathrm{W}, 700 \mathrm{~m}$ alt. beira de riacho, área perturbada, solo arenoso.

CFC :R 12991 - 130)1 - Margem do Ribeirão das Mortes, próximo da ponte, $16^{\prime \prime} 35^{\prime} \mathrm{S}, 42^{\prime \prime} 54^{\prime} \mathrm{W}, 760 \mathrm{~m}$ alt.

CFCR 13002 - 13020 - Estrada do campo de aviação, 16"32'S, $42^{\circ} 49^{\prime} \mathrm{W}, 950 \mathrm{~m}$ alt. - mata montana.

CF(CR 13021 - 13027 - Subida para o morro Papo-da-Ema, entre

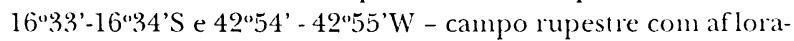
mento de rocha quartzítica.

CFCR 13028 - 13050) - Alto do morro Papo-da-Ema, $960 \mathrm{~m}$ alt.

CFCRR 13051 - 13110 - Descida do morro Papo-da-Ema para o Janbeiro, $850 \mathrm{~m}$ alt.

CFCR 13111-13160 - Estreito do riacho Ribeirão, 16"33'S, 42"54'W', 950-1000 $\mathrm{m}$ alt.

CFCR 13161 - Córrego da Bonita, perto da ponte da Estrada para Francisco Sá, $700 \mathrm{~m}$ alt.

CFCR 13162 - 13197 -Adjacências do córrego Escurona, 16"35'S, $42 " 58$ 'W, $750 \mathrm{~m}$ alt. - cerrado.

Expedição 16. 4 - 10.IX.1990 - Cl.CK 13234- 13541

Col. J.R. Pirani, G.L. Esteves, M.T.V. A. Campos \& T.R.S. Silva.

CFCK 13234 - 13297 - Vale do rio Itacambiruçu, 16"36' $-42^{\prime \prime} 55^{\prime} \mathrm{W}$, $670 \mathrm{~m}$ alt. - solo arenoso-fino com af loramentos rochosos, com cerrado, carrasco e vegetação rupícola.

CFCR 1329 - 13318 - Fazenda Jambeiro à margem da rodovia GrãoMogol-Francisco Sá, Córrego da Bonita, 16“35’S, 42“56’ W, 700m s.m. - campo e cerrado de solo arenoso fino.

CFCR 13319-13338 - Vale do córrego Escurona, 16"35'S, 42"58' W, $750 \mathrm{~m} \mathrm{s.m.} \mathrm{-} \mathrm{área} \mathrm{de} \mathrm{cerrado} \mathrm{com} \mathrm{afloramentos} \mathrm{quartzíticos.}$
CFCR 13339 - 13387 - Estrada para o rio Ventania, 16"35'S, 42 $49^{\circ} \mathrm{W}$, $900 \mathrm{~m}$ alt. - cerrado, solo areno-pedregoso.

CFCR 13388 - 13399 -Estrada para o rio Ventania, 16"35'S, 42"49' $\mathrm{W}$, $900 \mathrm{~m}$ alt. - mata montana e transição cerrado-mata.

CFCR 1340() - Vila Nova, a cerca de $1 \mathrm{~km}$ da cidade na estrada para o rio Ventania, 16"34'S - 42"53'W, $900 \mathrm{~m}$ alt.

CFCR 13401 - 13474 - Estreito do riacho Ribeirão, 16“33'S - 42"54'W, $950 \mathrm{~m}$ alt.

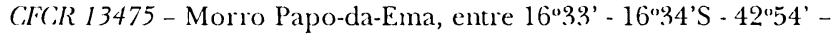
$42^{\circ} 55^{\prime} \mathrm{W}$.

CFCR 13476 - 135(1) - Alto do Morro do Jambeiro, flanco da descida para o córrego Escurinha.

CFC:R 13503 - 13541 - Córrego da Bonita, subida para o morro Jambeiro, 16"35'S - 42"56'W.

Expedição 17. 12-15.VI.1991. Mello-Siltua el al. 465-481 Col. R. Mello-Silva, M.L.F. Salatino, A. Salatino \& P. Affonso. 465 - 468 - Córrego Escurona.

469 - 472 - Margens do rio Itacambiruçu, fazenda Jambeiro.

$473-476-4 \mathrm{~km}$ da cidade, baixada do rio Itacambiruçu.

$477-478$ - Perímetro urbano, norte da cidade.

$479-481$ - Ribeirão dos Bois.

Expedição 18. 25-29.IX.1997. Mello-Siltua el al. 1416-1446, Rapini el al. 331-401

Col. R. Mello-Silva, M.L.Kawasaki \& A. Rapini.

Mellor-Silva el al. 1416-1420 - Vale do rio Itacambiruçu.

1421 - 1425 - Margens do rio Itacambiruçu, fazenda Jambeiro.

1426 - 1444 - Trilha da Tropa.

1445 - Ribeirão dos Bois.

1446 - Vale do rio Itacambiruçu.

Rapini el al. 331 - 336 - Vale do riacho Jambeiro, ca. 10 km de GrãoMogol, na estrada para Francisco Sá.

337 - Margem do rio Itacambiruçu, a montante da estrada para Cristália, $650 \mathrm{~m}$ s.m.

338 - 339 - Trilha da Tropa, que vai para Periperi, nas encostas à esquerda do Ribeirão do Inferno, $900 \mathrm{~m} \mathrm{s.m.}$

341) - 342 - Trilha da Tropa, que vai para Periperi, nas encostas à esquerda do Ribeirão do Inferno, $1000 \mathrm{~m} \mathrm{s.m.}$

343 - Contrafortes a leste da Trilha da Tropa, $1000 \mathrm{~m} \mathrm{s.m.}$

344 - 345 - Contrafortes a lesta da Trilha da Tropa, $1230 \mathrm{~m} \mathrm{s.m.}$

346 - Vale do rio Itacaubiruçu, próximo à ponte para Cristália, 650 $\mathrm{m}$ s.m.

347 - 4() - Margem do rio Itacambiruçu, a montante da estrada para Cristália, $650 \mathrm{~m} \mathrm{s.m.}$

Expedição 19. 9-13.III.1998. Rapini Eे Kawasaki 73(1)-752

Col. A. Rapini \& M.L. Kawasaki.

$73(1)-731-32$ knn de Grão-Mogol em direção à Cancela, na BR-251. $732-75()$ - Serrarial, ca. $16^{\circ} 25^{\prime} \mathrm{S}, 42^{\circ} 55^{\prime} \mathrm{W}$.

751 - Ca. 13 km de Grão-Mogol, margem do Córrego Escurona, ca. $16^{\circ} 35^{\prime} \mathrm{S}, 42^{\circ} 57^{\prime} \mathrm{W}$.

752 - Próximo à Torre de TV, ca. 16³5’'S, 4253'W.

Expedição 20. 1.3-17.V.1998. I'irani el al. 43(19-4351, Forzza el al. S()1S(1)6, Marcalo el al. 196-2017

Col. J.R. Pirani, A.C. Marcato, R.C. Forzza, M.C. Assis \& P.H. Labiak. Pirani el al. 4309 - 4320 - Vale do rio Itacambiruçu, Jambeiro, $16^{\circ} 35^{\prime} 35^{\prime \prime} \mathrm{S}, 42^{\circ} 55^{\circ} 05^{\prime \prime} \mathrm{W}, 660 \mathrm{~m}$ alt.

4321 - 4323 - Estrada para Francisco Sá, encosta do Córrego da Bonita, $16^{\circ} 35^{\prime} 23^{\prime \prime S}, 42^{\circ} 55^{\prime} 40^{\prime \prime} \mathrm{W}^{\prime}, 760 \mathrm{~m}$ alt. - campo rupestre e orla de mata ciliar. 
4324 - 4327 - Estrada para Cristália, fazenda Matão, 16³6’'S, $42^{\circ} 51^{\prime} \mathrm{W}$ - mata mesófila.

4328 - 4330) - Estrada perto do campo de aviação - mata mesófila perturbada.

4331 - 4335 - Estrada do Barão, Serra do Barão, ca. $500 \mathrm{~m}$ a 2 km da cidade - campo rupestre e encostas rochosas quarzíticas.

4336 - 4338 - Vale do rio Itacambiruçu, estrada para Cristália, ca. 1 $\mathrm{km}$ além da ponte sobre o rio, $660 \mathrm{~m}$ alt. - vegetação arbóreoarbustiva sobre solo arenoso.

4339 - 4348 - Chapada do Bosque (Chapada do Cardoso na Folha IBGE), Fazenda Vargem Redonda, ca. $11 \mathrm{~km}$ em ramal da estrada Grão-Mogol-Salinas, $16^{\circ} 29^{\prime} 37^{\prime \prime} \mathrm{S}, 42^{\circ} 52^{\prime} 59^{\prime \prime} \mathrm{W}, 780 \mathrm{~m}$ alt. campo rupestre e burutizais.

4349 - 4351 - Taquaral, ca. $8 \mathrm{~km}$ em ramal da estrada Grão-MogolSalinas, ca. $16^{\circ} 29^{\prime} \mathrm{S}, 42: 52^{\prime} \mathrm{W}, 760 \mathrm{~m}$ alt. - cerrado de encosta.

Forzza el al $8(1) 1$ - campo rupestre.

$8(1) 2$ - mata ciliar.

$8(13-804$ - borda de mata ciliar.

805 - 806 - campo rupestre.

Marcato et al. 196-198-Vale do rio Itacambiruçu, Jambeiro, $660 \mathrm{~m}$ s.m. - cerrado arenoso.

199 - 201 - Córrego da Bonita, 760m alt. - mata de galeria.

202 - 203 - Estrada para Cristália, fazenda Matão - mata mesófila.

204 - 207 - Chapada do Bosque, $780 \mathrm{~m}$ alt. - campo arenoso próximo a buritizal.
Expedição 21. 20-25.III.2000. Pirani el al. 4573-4589, Fiaschi et al. 164-176, Lima et al 89-98

Col. J.R. Pirani, P. Fiaschi, L.R. Lima \& J.P. Cometti.

Pirani el al. 4573 - 4575 - Vale do rio Itacambiruçu, Jambeiro, $16^{\circ} 35^{\prime} 35^{\prime \prime} \mathrm{S}, 42^{\circ} 55^{\prime} 05^{\prime \prime} \mathrm{W}, 660 \mathrm{~m}$ alt.

4576 - 4588 - Estrada do Barão, Serra do Barão, ca. 500m a 2 km da cidade - campo rupestre e encostas rochosas quarzíticas.

4589 - Ribeirão dos Bois - afloramento rochoso.

Fiaschi el al. 164 - Vale do rio Itacambiruçu, ca. 16*35'35"S, $42^{\circ} 55^{\prime} 05^{\prime \prime} \mathrm{W}$ - cerrado em solo arenoso.

165 - 166 - Estrada Francisco Sá - Grão-Mogol, base do morro Jambeiro, $16^{\circ} 34^{\prime}, 42^{\circ} 56^{\prime} \mathrm{W}$.

167 - 172 - Trilha para o alto da Serra do Barão, $16^{\circ} 32^{\prime} \mathrm{S}, 42^{\circ} 55^{\prime} \mathrm{W}$.

173 - 174 - Estrada para o rio Ventania, ca. $6,5 \mathrm{~km}$ do Ribeirão dos Bois, ca. $16^{\circ} 34^{\prime} \mathrm{S}, 42^{\circ} 52^{\prime} \mathrm{W}$.

175 - 176 - Ramo vicinal da estrada para o rio Ventania, ca. $2 \mathrm{~km}$ do Ribeirão dos Bois.

Lima el al. 89 - 92 - Vale do rio Itacambiruçu, ca. $16^{\circ} 35^{\prime} \mathrm{S}, 42^{\circ} 55^{\prime} \mathrm{W}$ - afloramento rochoso, solo arenoso úmido.

93 - 96 - Estrada da Serra do Barão, ca. $16^{\circ} 32^{\prime} \mathrm{S}, 42^{\circ} 55^{\prime} \mathrm{W}$ - afloramento rochoso.

$97-98^{\prime}$ - Ribeirão dos Bois, estrada para o rio Ventania, ca. $16^{\circ} 33^{\prime} \mathrm{S}$, $42^{\circ} 52^{\prime} \mathrm{W}$ - cerrado de altitude. 